\title{
A Study on the Response of the lonosphere to the Three Major Space Weather Events of 2015 Using a Meridional Chain of lonosondes and GPS Receivers Over India
}

\author{
S. Sripathi and Ram Singh \\ Indian Institute of Geomagnetism, Navi Mumbai, India \\ E mail (ssripathi.iig@gmail.com/ sripathi@iigs.iigm.res.in).
}

Accepted: 3 April 2020

\begin{abstract}
A comparative study is made on the response of the equator and low latitude ionosphere to three major storms in 2015, namely 17-18 March (St. Patrick's Day), 22-23 June and 19-20 December, using ionosondes and GPS receivers over the Indian sector. We use observations of foF2 $(\mathrm{MHz})$, h'F $(\mathrm{km})$, equatorial Spread F, L-band scintillations and TEC for this study. As these storms fell on three seasons, the study examines the role of storm-time changes in the composition, winds, waves and electric fields and their interaction with density under these seasons for the occurrence of plasma irregularities and positive and negative ionospheric storms. We noticed positive (negative) storm in December (June) in the main phase. We also noticed positive (negative) storm at the equator (low latitude) during March in the recovery phase. The h'F $(\mathrm{km})$ at the equator is modified significantly by the orientation and magnitude of the storm-time zonal electric field. While the St. Patrick's Day storm showed an abrupt increase of $h^{\prime} F(\mathrm{~km})$ due to the absence of low latitude Es layers and addition of an eastward electric field to the existing post-sunset enhancement of eastward electric field leading to the generation of severe plasma irregularities and L-band scintillations at wide latitudes, plasma irregularities and scintillations are suppressed during June in the midnight sector due to westward electric field. However, during December, a sudden increase of h'F $(\mathrm{km})$ in the pre-dawn sector caused generation of plasma irregularities. The results further suggest that the ionosphere over India is significantly modified by the storm processes in the night sector during winter due to efficient coupling.
\end{abstract}

(c) 2020 BBSCS RN SWS. All rights reserved

Keywords: Geomagnetic storms; spread F; L-band scintillations; positive storms; negative storms; seasonal variation; TEC variations; low latitude electrodynamics

\section{Introduction}

The occurrence of geomagnetic storms due to interaction of the solar wind and magnetosphere under disturbed conditions plays a significant role in coupling processes between various regions of the upper atmosphere in the high latitudes and also to lower latitudes. During geomagnetic storms, particle precipitation and Joule heating cause large density perturbations in addition to electric and magnetic field disturbances. The atmospheric motion due to Joule heating in the presence of a magnetic field causes auroral currents. However, if these currents don't flow due to a conductivity gradient, polarization electric fields are generated. These electric fields then map to equatorial and low latitudes and produce significant modifications in the electron density (e.g., Wolf, 1975; Fuller-Rowell et al., 1997; Buonsanto, 1999; Kamide and Chian, 2007; Sharma et al., 2003; Mendillo, 2006). Geomagnetic storms not only can influence the performance and reliability of spaceborne technological systems through increased density and increased ion drag in the upper thermosphere, but also can disturb the lower thermosphere through deposition of additional ionization at high latitudes (e.g., Lastovicka, 1996; Hapgood, 2017). During extreme space weather events, the Coronal Mass Ejections (CMEs) as ejected from the Sun blow toward the Earth where they interact with Earth's magnetosphere. Due to the magnetic reconnection, the stored energy in the tail side of the Earth discharges partial energy into the high latitude ionosphere while the remaining partial energy is utilized to produce the ring current at low latitudes (e.g., Kamide and Chian, 2007; Weiss et al., 1992; Kamide et al., 1997; Vichare et al., 2005). The heating generated at high latitude due to particle precipitation and Joule heating during geomagnetic storms plays a significant role in the redistribution of composition, ionospheric electron density and conductivity at all latitudes including equatorial and low latitudes (e.g., Fuller-Rowell et al., 1996; Mayr et al., 1990). The energy generated due to this heating blows toward the equator due to differential heating in the form of neutral winds and electric fields, and modifies the neutral composition, namely the $\mathrm{O} / \mathrm{N} 2$ ratio, which produces positive and negative ionospheric storms at mid and low latitudes (e.g., Richmond and Matsushita, 1975; Rishbeth, 1975; Blanc and Richmond, 1980; Hajkowicz, 1990; Somayajulu, 1991; Richmond and $\mathrm{Lu}, 2000$; Bagiya et al., 2011). These storms can affect satellites by increasing ion drag and also affect navigation and communication systems significantly by modifying the ion density. The vertical winds generated at high latitudes carry molecular-rich air to higher altitudes. The vertical winds also transport the composition (mainly N2) to lower latitudes such as mid and low latitude regions which is often known as 'composition bulge'(e.g., Richmond and Matsushita, 1975; Rishbeth, 1975; Fuller-Rowell and Codrescu, 1994; Fuller-Rowell et al., 1996; Prolss, 1997). Even though the magnetospheric energy is the same for both polar regions, they produce asymmetric energy deposition due to asymmetric distribution of densities and conductivities in the solstices. The seasonal variation in the neutral composition is believed to be influenced by the storm magnitude, phase of the storm and its time history. Positive and negative ionospheric storms are developed at mid and low latitudes due to asymmetric distribution of composition (e.g., Burns, 1995; Lu et al., 1995; 2001; Mendillo, 2006; Zhao, 2012; Balan et al., 2010; Prölss, 2017). Fuller-Rowell et al. (1996) have performed a simulation study during equinox, summer and winter to understand the role of composition and thermospheric winds on the ionospheric density. Their results suggest that ionospheric density is significantly modified during solstices at mid and low latitudes due to composition bulge, as well as meridional winds. When the mean molecular mass density is increased drastically due to composition bulge in the summer hemisphere, ionization densities are decreased due to higher recombination leading to the negative storms. However, when a decrease of mean molecular mass is seen in the winter hemisphere, the ionization density is increased due to lower recombination leading to the positive ionospheric storms. During geomagnetic storms, electric fields can promptly penetrate to equatorial and low latitudes due to 
imbalance between Region1 and Region2 and can affect the low latitude dynamics. This is often known as prompt penetration electric fields (PPEFs) (e.g., Singh et al., 2015; Singh and Sripathi, 2017 and references therein). In addition, disturbance dynamo electric fields (DDEF) as generated at mid-latitudes due to wind circulation can affect the low latitude ionosphere, though with a delay of a few hours (e.g., Blanc and Richmond, 1980). The geomagnetic storms significantly affect the equatorial spread $\mathrm{F}$ irregularities and scintillations based on modifications in the equatorial electric fields by these additional fields (e.g., Abdu, 1997). As we are becoming more dependent on space-based technologies, understanding space weather and its impacts on navigation and communication systems is very important. Accordingly, understanding navigation systems such as GPS satellites through signal attenuation in the radio signals is essential for extreme space weather events such as the Carrington event (e.g., Mannucci, 2005; Hapgood, 2017).

Since each storm can be distinctive, studying their impacts on the ionosphere and thermosphere can provide important clues that may be useful to identify physical mechanisms among different regions and their characteristics (e.g., Verkhoglyadova et al., 2016). Recent geomagnetic storms observed during 2015, namely 17-18 March 2015 (i.e., the St. Patrick's Day storm), 22-23 June 2015 and 19-20 December 2015, are very unique in the sense that they are observed in the same year with near similar magnitude but under different seasons. Also they are the only major storms of the solar cycle-24 and hence it is important to know their physical significance. It is interesting to study the ionospheric response at equatorial and low latitudes during these storms under three seasons to examine the background conditions that modify the winds and electric fields. Accordingly, in this paper, we present results from these three space weather events and discuss them with reference to these background conditions. It is known that quiet-time winds blow away from the equator to low latitudes during daytime in the equinoctial condition and vice versa during night time. However, during solstice seasons, the winds blow from the summer hemisphere to winter hemisphere through equator. In addition, the daytime primary eastward electric field causes vertical E X B drift to push the electron density to higher latitudes during daytime at equatorial locations through magnetic field lines to form equatorial ionization crests on either side of the equator. However, the location and strength of the density of these crests are affected by the meridional winds. If meridional winds are blowing from the summer hemisphere to winter hemisphere, they can modify the $\mathrm{O} / \mathrm{N}_{2}$ ratio to reduce the density at the crest in the summer hemisphere, but they can increase the density in the winter hemisphere. Accordingly, these meridional winds are significantly affected during solstices. Also, during geomagnetic storms due to modifications in the composition along with enhanced winds that blow from auroral latitudes to low latitudes, the winds can either add or suppress the existing ion densities to produce either positive storms or negative storms. So, these interactions can ultimately lead to complex electrodynamics in the equatorial and low latitude ionosphere. Accordingly, this paper discusses the storm time disturbances produced due to major storms observed on 17-18 March 2015 (i.e., the St. Patrick's Day storm), 22-23 June 2015 and 19-20 December 2015 in the same year with near similar magnitude but under different seasons using a network of ionosondes over the Indian sector. The observations presented in this paper will be discussed in terms of the seasonal behaviour of the ionospheric density as well as the effect of storm time electrodynamics due to DDEF and PPEF on the night-time equatorial plasma irregularities.

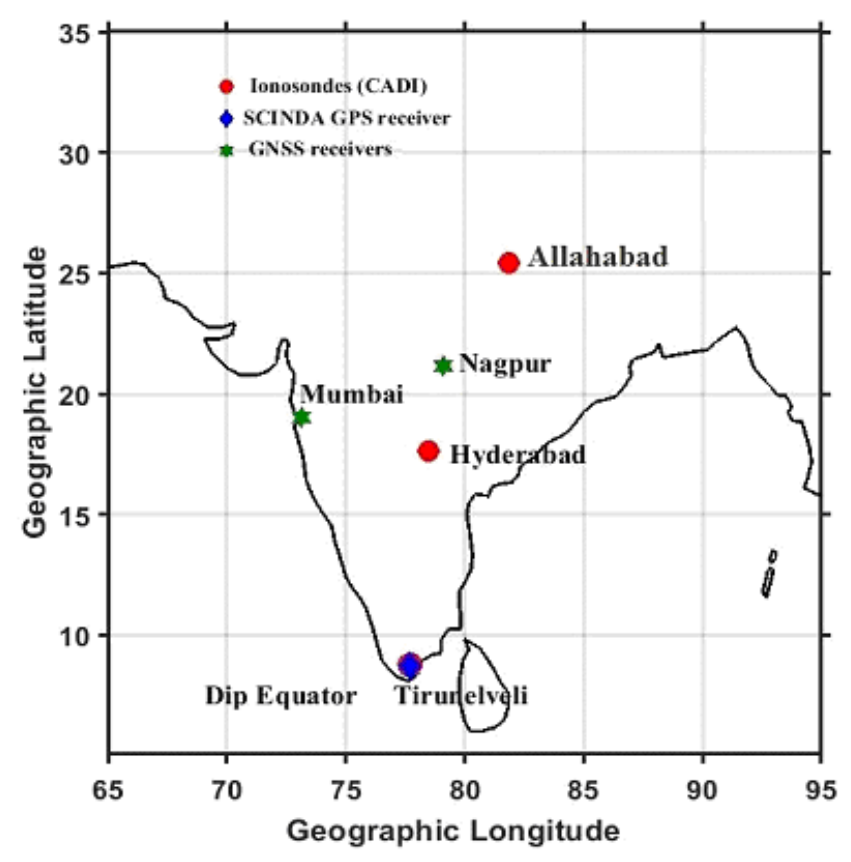

Figure- 1 shows the location of ionosondes and GPS receivers superposed onto the India map

\section{Data and data analysis}

In this section, we describe the observations of Canadian Advanced Digital Ionosonde (CADI) as obtained from the Tirunelveli, Hyderabad and Allahabad stations. The CADI ionosonde works on the principle of total reflection where it sweeps frequencies from 1-20 MHz. It uses a delta antenna for transmission and 4 receivers are arranged in a square with $15 \mathrm{~m}$ length on each side for reception. Depending upon the delay time, the reflection height is measured which is known as 'virtual height.' As it sweeps several frequencies, the reflections from different heights are expected. If we convert these reflected signals into digital form, they form an echogram which is often called an 'ionogram.' The reflected signal as received at four different directions can provide information about the movement of the echo region. Using cross spectral analysis among these receivers, it is possible to measure horizontal and vertical drifts using a Doppler interferometry technique using fixed frequency measurements (e.g., MacDougall, 1995). While Doppler drifts are measured between successive ionograms, a single ionogram is produced at 10/15 minutes depending upon the number of sweeping frequencies used. Similarly, we utilized L-band scintillations and TEC observations as obtained from GPS/GNSS receivers located at Tirunelveli, Mumbai and Nagpur along the Indian longitude. The slant TEC is then converted into vertical TEC using a suitable mapping function at $350 \mathrm{~km}$ as mentioned in Ramsingh et al. (2015). Figure-1 shows a map of India with the locations of CADI ionosondes and GPS receivers which are used in the present analysis. In addition, we also utilized GPS TEC from IGS stations in the Indian region along with processed Madrigal GPS TEC maps to compare our ionosonde observations during these storm events. The solar and geomagnetic data as obtained from NASA websites are also utilized. 

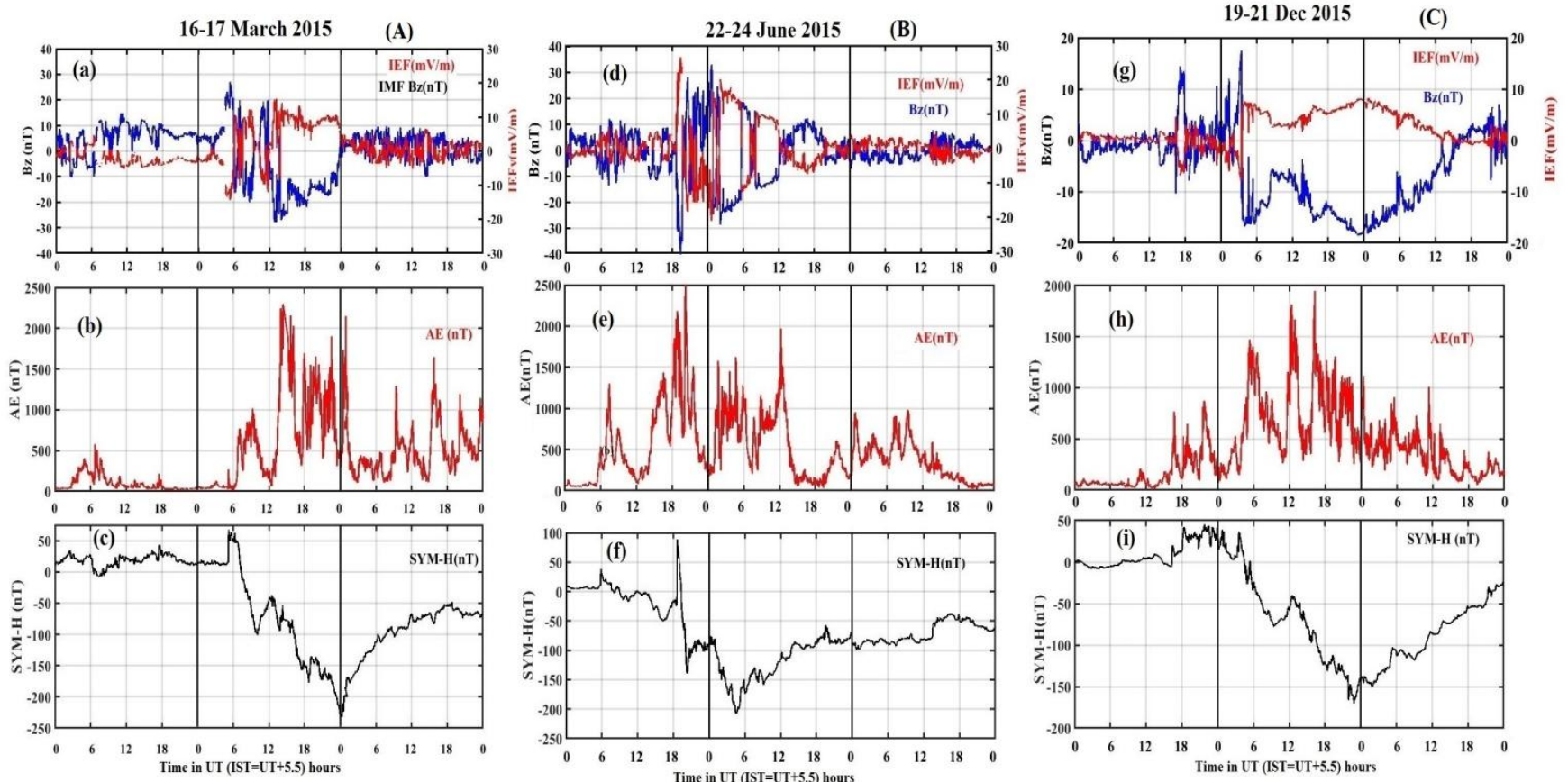

Figure-2 shows the temporal evolution of solar, interplanetary and geomagnetic parameters during 17-18 March 2015 storm ((left) top to bottom), 22-23 June 2015 storm ((middle) top to bottom) and 19-22 December 2015 storm ((right) top to bottom)

\section{Interplanetary/Geomagnetic activity levels during these storms}

In this section, we present inter-comparison of interplanetary and geomagnetic activity levels during these three major storms. Table- 1 shows the comparison of various solar, interplanetary and geomagnetic parameters and their onset times during these major space weather events. Next, each storm is described separately.

\section{(a) 17-18 March 2015 storm}

The first super geomagnetic storm of solar cycle 24 occurred on $17^{\text {th }}$ March 2015 (on St. Patrick's Day) with the SYM-H (Dst) value $\sim-228 \mathrm{nT}$. The impact of this geomagnetic storm initially was seen as a mild G1-class storm $(\mathrm{Kp}=5)$ but this magnetic storm intensified into G4-class $(\mathrm{Kp}=8)$ later. This geomagnetic storm was associated with the C9.1 F flares (S22W25) and a series of type II/IV radio bursts. The blue and red colour plots in Figure $2 \mathrm{a}$ show the variation of the interplanetary magnetic and electric fields. Figure- $2 b$ shows the variation of the auroral electrojet (AE) index which is an indication of substorm activity. The source of this geomagnetic storm was a partial halo coronal mass ejection (CME) which was recorded by SOHO/LASCO C3 coronagraph imagery on 15 March 2015 at 02:10 UT. This CME reached the Earth on 17 March at 04:45 UT which caused magnetopause compression as indicated by sudden storm commencement (SSC) where the SYM-H value reached $\sim 70 \mathrm{nT}$ as shown in Figure-2c. During the SSC phase, the interplanetary magnetic field (IMF Bz) reached its most positive value of $\sim 25 \mathrm{nT}$ (in Figure-2a, blue colour). On 17 March at around 06 UT, when a sudden southward turning is observed in the IMF Bz, the geomagnetic storm was initiated. At the same time, SYM-H also started decreasing indicating the onset of the main phase which reached its minimum value of $-100 \mathrm{nT}$ at $09 \mathrm{UT}$. After that the IMF $\mathrm{Bz}$ slowly went back to northward before it again turned southward. It is a two step process where SYM-H reached around $-228 \mathrm{nT}$ at $00 \mathrm{UT}$ on 18 March 2015 indicating the end of the main phase. The recovery phase of the geomagnetic storm started afterwards and continued 18-19 March. The AE index shows multiple substorms as can be seen in Figure- $2 \mathrm{~b}$.

\section{(b) 22-23 June 2015 storm}

The second largest geomagnetic storm of the solar cycle 24 occurred on 22-23 June 2015. The minimum Dst observed during the magnetic storm was around $-207 \mathrm{nT}$. The impact of this geomagnetic storm was severe with $\mathrm{G} 4$-class $(\mathrm{Kp}=8)$. The source of this geomagnetic storm was two CMEs which were observed by SOHO/LASCO coronagraph imagery at around 05:50 UT on 19 June. The first CME reached the Earth at around 05:45 UT on 22 June and generated a small shock and enhanced SYM-H indicating onset of the SSC phase as shown in Figure-2f. After that, another shock was observed with significant changes in the geomagnetic conditions due to the arrival of second CME on 22 June at around 18:30 UT where the SYM-H value was enhanced to $\sim 90 \mathrm{nT}$ (Figure-2f). The AE index jumped from $\sim 500 \mathrm{nT}$ to $\sim 2300 \mathrm{nT}$ (Figure-2e) at the same time, indicating onset of substorm activity. The IMF $\mathrm{Bz}$ component (blue colour plot in Figure-2d) suddenly turned southward with its minimum value of $\sim-40 \mathrm{nT}$ at 19:30 UT on 22 June when a second shock was observed indicating the onset of a geomagnetic storm. The storm main phase was observed when sudden decrease in SYM-H is observed. At the same time IEFy reached up to $\sim 25 \mathrm{mV} / \mathrm{m}$ (red colour plot in Figure-2d). During the main phase, SYM-H initially reached a minimum value of $\sim 133 \mathrm{nT}$ on 22 June at $\sim 20: 30$ UT and after that it again pushed further to a minimum value of $\sim-207$ nT on 23 June at $\sim 04: 30$ (Figure-2f). The multiple substorms can be seen in the $\mathrm{AE}$ index as shown in Figure-2e. The recovery phase is characterized by an increase in the $\mathrm{H}$ component which slowly recovered to the normal behaviour on the 23-24 June.

\section{(c) 19-21 December 2015 storm}

The third major geomagnetic storm in the solar cycle-24 with the minimum Dst of -175 nT is observed during 19-21 December 2015. Figure-2(g-i) shows interplanetary and geomagnetic conditions during the 19-21 December 2015 storm. The source of this geomagnetic storm was two Earth-directed asymmetrical full halo CMEs, which were observed at $~ 09: 25$ and 14:35 UT, respectively, on 16 December by the SOHO/LASCO C2 coronagraph imagery. Both CMEs merged in the interplanetary medium and reached the Earth at $~ 15: 30$ UT on 19 December and generated the storm as shown in Figure-2i. The onset of the geomagnetic storm started around 15:30 UT on 19 December and 
at the same time the interplanetary magnetic (the blue line in Figure-2g) and electric (the red line in Figure-2g) fields show abrupt changes in value. The IMF Bz shows northward turning during the SSC phase and reached a value of $15 \mathrm{nT}$. The main phase of the geomagnetic storm started on 20 December at around 04 UT when IMF Bz turned southward and reached a value of -15 nT. This southward IMF Bz is continued for about 36 hours. When IMF Bz was fluctuating in the southward orientation itself, the intensification of auroral activities was also noticed which are an indication of substorm activity. The $\mathrm{AE}$ index enhanced its maximum value $\sim 1800 \mathrm{nT}$ (in Figure-2h). Initially it was seen as a moderate geomagnetic storm with the intensity of the SYM-H value around $-88 \mathrm{nT}$ at around 08:30 UT but later the storm intensified. The SYM-H reached its minimum value of $\sim-175 \mathrm{nT}$ during the second step on 20 December at around 23 UT. The recovery phase of the geomagnetic storm started afterwards which continued for a week or so in December. At the same time, IMF $\mathrm{Bz}$ also slowly started to turning northward after prolonged continuation of a southward direction as can be seen in Figure-2g.

Table-1 shows the comparison of important solar, interplanetary and geomagnetic parameters and their onset times during March, June and December 2015 major space weather events.

\begin{tabular}{|c|c|c|c|}
\hline \multicolumn{4}{|c|}{ Geomagnetic Storm (Intense, Dst $\leq \mathbf{- 1 0 0}$ ), solar Cycle :24 } \\
\hline Event & 17 March 2015 & 23 June 2015 & 20 Dec 2015 \\
\hline Cause & $\begin{array}{c}\text { Partial Halo CME } \\
\text { Speed } 719 \mathrm{~km} / \mathrm{sec}\end{array}$ & $\begin{array}{c}\text { Two Halo CMEs } \\
\text { Speed } \sim 1366 \text { km/sec }\end{array}$ & $\begin{array}{c}\text { Two Halo CMEs } \\
\text { Speed } \sim 480 \mathrm{~km} / \mathrm{sec}\end{array}$ \\
\hline Observed time & $\begin{array}{c}\text { At } \sim 15 / 02: 10 \mathrm{UT} \\
\text { SOHO/LASCO }\end{array}$ & $\begin{array}{c}\text { At } \sim 19 / 05: 50 \mathrm{UT} \\
\text { SOHO/LASCO }\end{array}$ & $\begin{array}{c}\text { At } \sim 16 / 09: 25 \text { UT, } \\
\sim 16 / 14: 35 \text { UT } \\
\text { SOHO/LASCO }\end{array}$ \\
\hline $\begin{array}{l}\text { Hitting time of } \\
\text { Magnetosphere }\end{array}$ & At $\sim 17 / 04: 30 \mathrm{UT}$ & $\begin{array}{l}\text { At } \sim 22 / 05: 45 \text { UT } \\
\text { At } \sim 22 / 18: 35 \text { UT }\end{array}$ & At $\sim 19 / 15: 30 \mathrm{UT}$ \\
\hline $\begin{array}{l}\text { Solar wind and } \\
\text { Interplanetary } \\
\text { conditions }\end{array}$ & $\begin{array}{c}\text { Psw } \sim 17-40 \mathrm{nPa} \\
\text { Vsw } \sim 600 \mathrm{Km} / \mathrm{sec} \\
\mathrm{B} \sim 30 \mathrm{nT} \\
\mathrm{IMF} \mathrm{Bz} \sim \pm 25 \mathrm{nT} \\
\mathrm{IEFy} \sim \pm 15 \mathrm{mV} / \mathrm{m} \\
\mathrm{AE} \mathrm{Index} 2200 \mathrm{nT} \\
\mathrm{SYM}-\mathrm{H} \sim-228 \mathrm{nT} \\
\mathrm{Kp}=8, \mathrm{Ap}=108\end{array}$ & $\begin{array}{c}\text { Psw } \sim 10-60 \mathrm{nPa} \\
\text { Vsw } \sim 550-760 \mathrm{Km} / \mathrm{sec} \\
\mathrm{B} \sim 41 \mathrm{nT} \\
\mathrm{IMF} \mathrm{Bz} \sim-39 \mathrm{nT} \\
\mathrm{IEFy} \sim \pm 25 \mathrm{mV} / \mathrm{m} \\
\mathrm{AE} \mathrm{Index} \sim 2500 \mathrm{nT} \\
\mathrm{SYM}-\mathrm{H} \sim-207 \mathrm{nT} \\
\mathrm{Kp}=8, \mathrm{Ap}=72\end{array}$ & $\begin{array}{c}\text { Psw } \sim 2-20 \mathrm{nPa} \\
\text { Vsw } \sim 350-550 \mathrm{Km} / \mathrm{sec} \\
\mathrm{B} \sim 17 \mathrm{nT} \\
\mathrm{IMF} \mathrm{Bz} \sim-20 \mathrm{nT} \\
\mathrm{IEFy} \sim \pm 9 \mathrm{mV} / \mathrm{m} \\
\mathrm{AE} \mathrm{Index} 1900 \mathrm{nT} \\
\mathrm{SYM}-\mathrm{H} \sim-174 \mathrm{nT} \\
\mathrm{Kp}=7, \mathrm{Ap}=72\end{array}$ \\
\hline
\end{tabular}
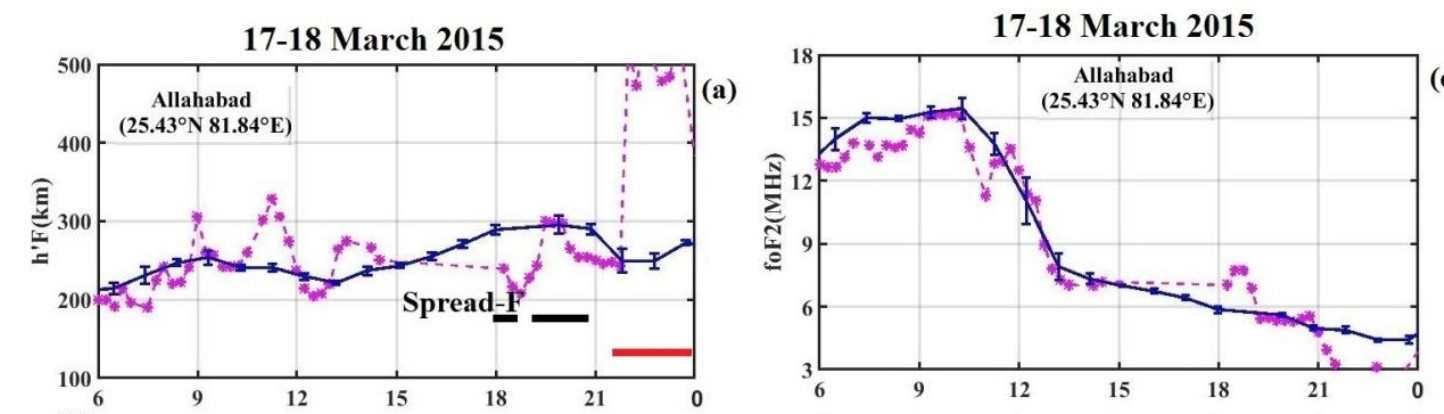

(d)

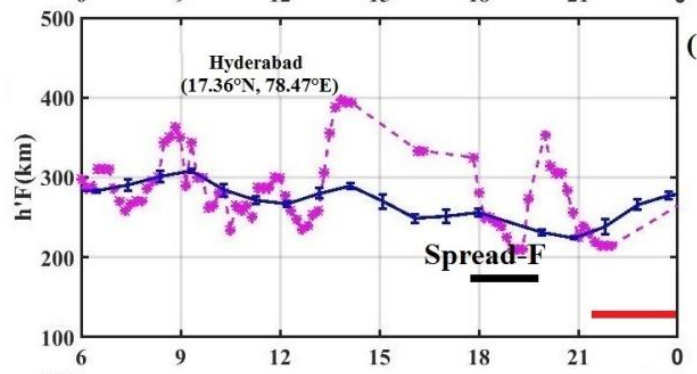

(b)
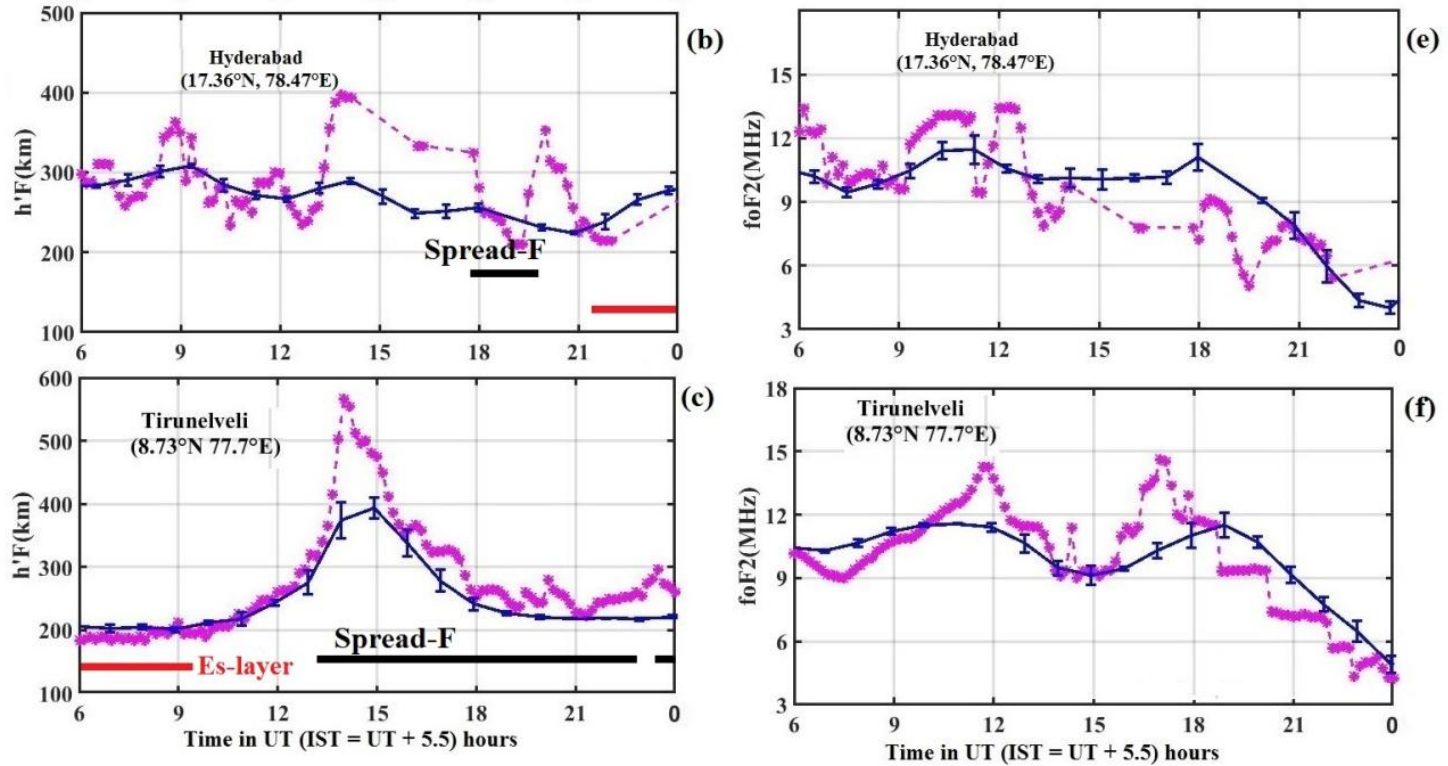

Figure-3(a-f) shows the h'F (km) (left plots) and foF2 (MHz) (right plots) at (a) ALD, (b) HYD and (c) TIR during 17-18 March 2015 storm 
22-23 June 2015
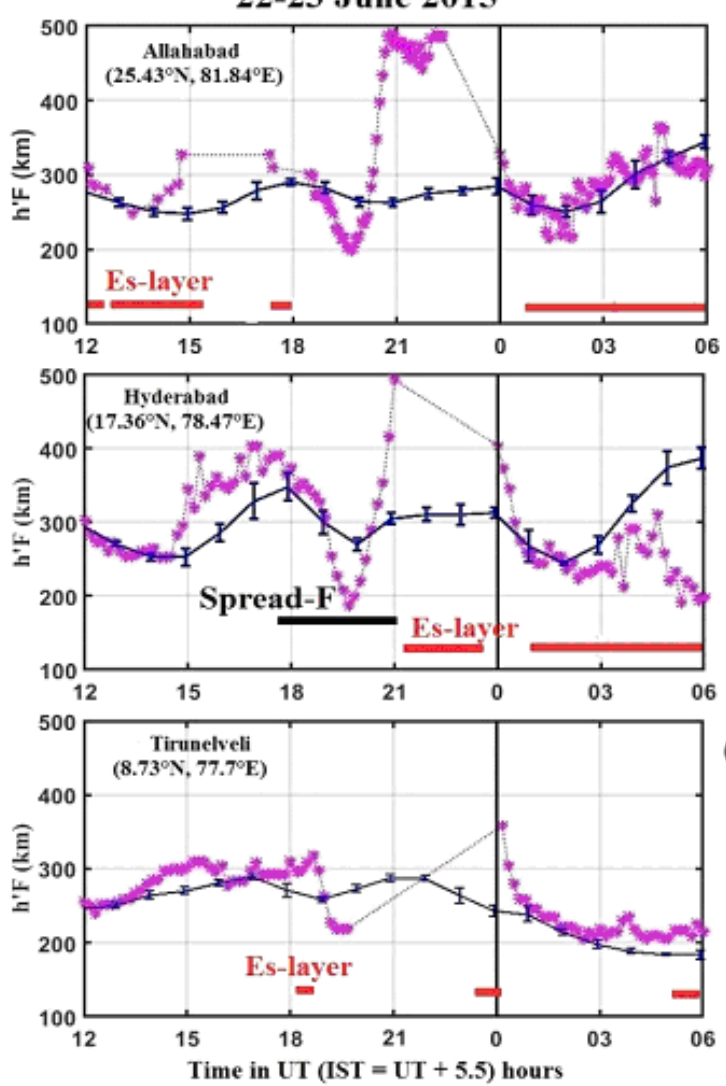

22-23 June 2015

(a)

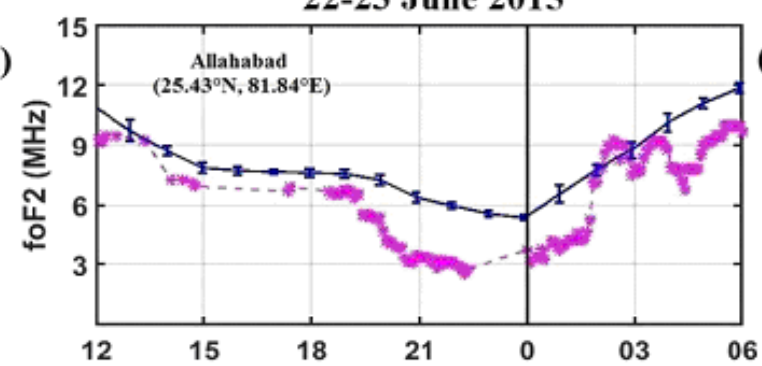

(b)

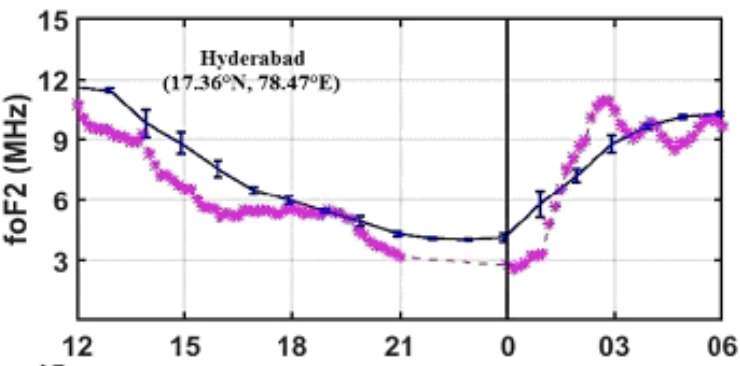

c)

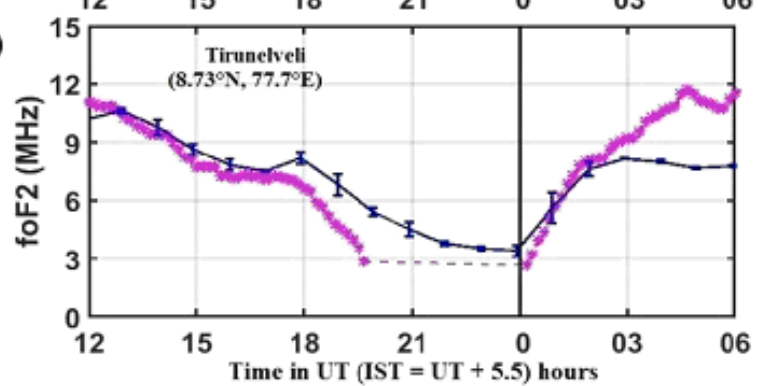

(e)

(d)

Figure-4(a-f) shows the h'F (km) (left plots) and foF2 (MHz) (right plots) at (a) ALD, (b) HYD and (c) TIR during 22-23 June 2015 storm

20-21 Dec 2015
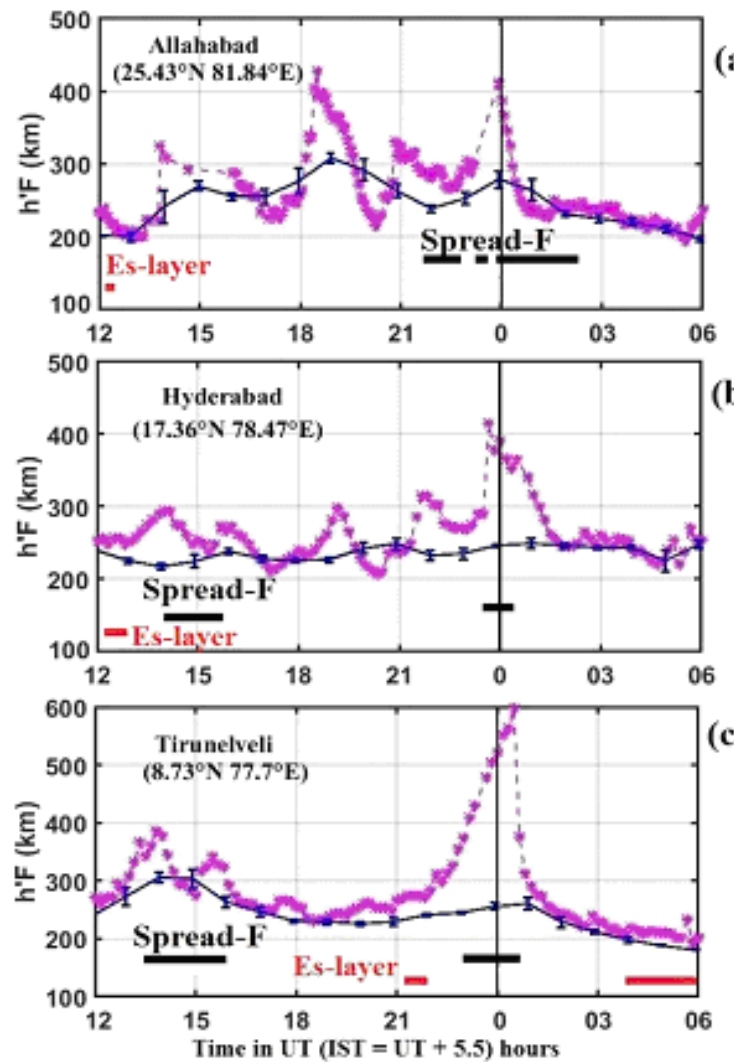

20-21 Dec 2015

a)

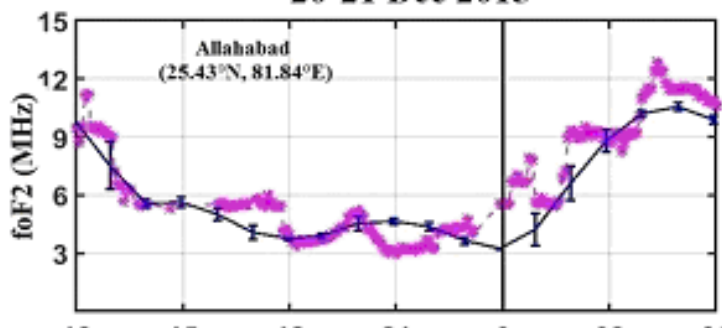

(b)

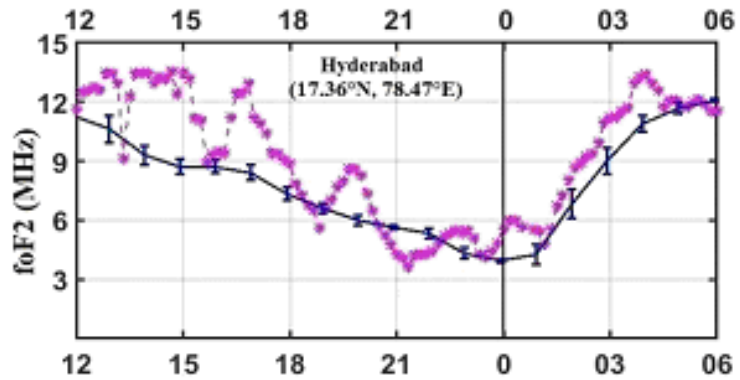

(e)

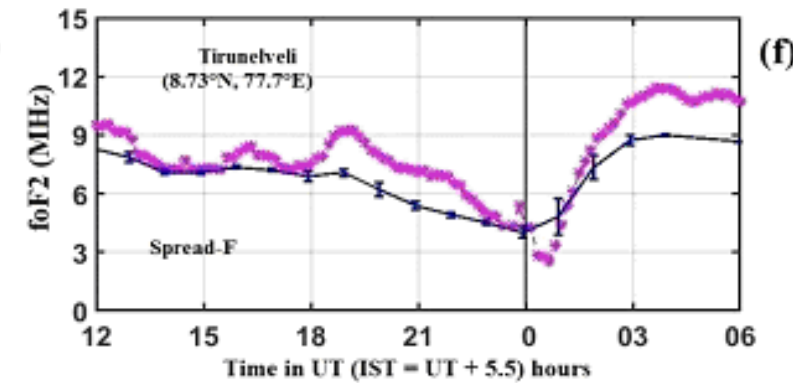

Figure-5(a-f) shows the h'F (km) (left plots) and foF2 (MHz) (right plots) at (a) ALD, (b) HYD and (c) TIR during 20-21 December 2015 storm 


\section{Observations}

Now we present the ionospheric response to these space weather events as observed over the Indian sector using a network of ionosonde stations. Figure-3(a-f) shows the h'F (km) (left) and foF2 (MHz) (right) plotted in thin 'red line' over (a) Allahabad (ALD), (b) Hyderabad (HYD) and (c) Tirunelveli (TIR) during the St. Patrick's Day storm (March 2015). Also shown in thin blue line in each subplot is the average value of five internal quiet days during March. The thick black and red lines in the each subplot indicate the occurrence of 'spread F' and 'blanketting Es layer', respectively. From the figure, we can understand the density and h'F variations with time at each station on storm day and its deviation from quiet time pattern. The important point to note is the rise of h'F in the post-sunset hours and associated density variations on the storm day simultaneously at each station. The temporal variation of h'F at TIR showed sudden deviation from its quiet time pattern in the post-sunset sector i.e. $13 \mathrm{UT}$ and rose to $\sim 560 \mathrm{~km}$. Immediately, equatorial spread $\mathrm{F}$ (ESF) or equatorial plasma irregularities started seen in the ionograms that continued until 06 IST (00:30 UT). It may be noted that the plasma irregularities are also known as electron density gradients that reflect or scatter the radio waves. The plasma irregularities are known to be generated due to plasma instabilities in the ionosphere. On the other hand, temporal variation of h'F at HYD and ALD showed its fluctuating values with respect to quiet time average pattern unlike TIR station. However, a simultaneous increase of h'F values were seen at both HYD and ALD stations when TIR height drastically rose to $\sim 560 \mathrm{~km}$. After that, as time progressed, the ionogram traces at both HYD and ALD stations disappeared until local midnight (18 UT). But after midnight, h'F at both HYD and ALD stations reappeared and showed slow descent and ascent trends with spread $\mathrm{F}$ occurrence. On the other hand, temporal variation of foF2 at TIR showed double peak density structure at 12 UT and 17 UT with mean foF2 values of 14 $\mathrm{MHz}$ and 14.5 MHz respectively. The foF2 variation at HYD showed many small peaks in density with mean enhancement in density of $13 \mathrm{MHz}$ during 09-13 UT with a brief dip at $11 \mathrm{UT}$ with a value of $9 \mathrm{MHz}$. Soon after that, the density started falling with density lows with a value of $5 \mathrm{MHz}$ but reached normal at 21 UT. Also it may be mentioned that ionogram quality got reduced from 14 UT with blank ionograms at many instances until 18 UT. At ALD, the trend of foF 2 showed its values below quiet time average value but following a similar pattern except a deep low with a density value of less than $12 \mathrm{MHz}$ at $11 \mathrm{UT}$. Also it may be noted that we observed blank ionograms during 15-18 UT which is usually the case on even quiet days.

Figure-4(a-f) shows the temporal variation of h'F (km) (left) and foF2 (MHz) (right) over (a) Allahabad (ALD), (b) Hyderabad (HYD) and (c) Tirunelveli (TIR) plotted in thin 'red line' during the 22-23 June storm which is quite similar to the Figure-3(a-f). The important point to note from this figure is the fall and rise of h'F in the local midnight sector (20 UT) and associated density variations on the storm day simultaneously at all the stations. The layer went up to $320 \mathrm{~km}$ at $18 \mathrm{UT}$ at TIR station slowly before it started descending down abruptly and reached $220 \mathrm{~km}$ at 19 UT. This value is quite low as compared to quiet day mean value which is varying around $260 \mathrm{~km}$. After that, it is noticed that no ionogram traces were visible during the period of 19-24 UT. At 00 UT (the next day), the layer became visible but only at higher altitudes at $360 \mathrm{~km}$. After that the layer slowly decreased as time progressed until 03 UT. After 03 UT, the layer was elevated to higher altitude and continued to vary above quiet time mean variation. The important point to note from the temporal variation of h'F at HYD and ALD is the simultaneous fall and rise of the h'F $(\mathrm{km})$ values in association with TIR h'F $(\mathrm{km})$. The fall and rise is very significant at these two stations than at TIR station. Also the important point to note is the occurrence of spread F only during post-midnight with their intensity and duration is higher at ALD followed by HYD and TIR. On the other hand, temporal variation of foF2 at TIR, HYD and ALD shows that they are below the quiet time value i.e. negative storm effect is noticed on 22 June. But on 21 June, the foF2 over TIR station showed its higher foF2 values than quiet time value during 03-06 UT. But they showed wave type structures at HYD and ALD station with their values fluctuating between quiet time values. Figure-5(a-f) shows the temporal variation of h'F (km) (left) and foF2 (MHz) (right) over (a) Allahabad (ALD), (b) Hyderabad (HYD) and (c) Tirunelveli (TIR) station plotted in thin 'red line' during the 20-21 December 2015 storm period quite similar to Figure-3(a-f). The important point to note from these plots is the large scale fluctuations in the h'F $(\mathrm{km})$ values at TIR, HYD and ALD stations unlike other two storms. Also spread F occurrence is seen during both in the post-midnight and post-sunset periods with post-sunset spread F is limited to only TIR and HYD stations. In addition to this, the foF2 variations at all three stations suggest that there is a positive storm effect over TIR station where foF2 is enhanced. But the foF2 variations over HYD and ALD stations suggest that they are very much fluctuating with mean quiet time variations.

Figure-6(a-c) shows the spatial and temporal variation of Lband scintillations during 17-18 March, 22-23 June 2015 and 2021 December 2015, respectively, over the Indian region. From the figure, it can be seen that L-band scintillations are more dominant during St. Patrick's Day than during the other two storms during solstice months. On careful examination of the figures, the presence of weak scintillations can be seen during these two storms. These results are in agreement with ionosonde observations of spread F. Figure-7(a-c) shows the temporal variation of percentage occurrence of spread $\mathrm{F}$ during quiet (blue) and disturbed (red) days during March, June and December months over TIR. Here the disturbed days and quiet days are identified based on the Ap index as described previously. From the figure, it can be noticed that spread $F$ occurrence is more dominant in March than June and December, and more dominant on quiet days than during disturbed days. During disturbed days, occurrence of spread $\mathrm{F}$ during pre-midnight is reduced very much during March as compared to June. However, during December, there is a slight increase in spread $\mathrm{F}$ occurrence during both premidnight and pre-sunrise hours. Interestingly, an increase in spread F occurrence can be seen during pre-sunrise in March as well. However, spread F occurrence during June seems to be reduced significantly during the entire night. Figure- $8(\mathrm{a}-\mathrm{c})$ shows the mean temporal and spatial variation of percentage of occurrence of L-band scintillations during quiet days, while Figure-8(d-f) shows the same information during disturbed days in March, June and December, respectively. From the figure, it can be seen that the occurrence of L-band scintillations during March is stronger during both quiet and disturbed periods as compared to June and December. During June, it can be seen that no L-band scintillations are present. However, during December weak scintillations can be seen in post-midnight during disturbed days. These results are similar to the trends presented using ionosonde observations.

Figure-9(a-f) shows the (a-c) quiet time and (d-f) disturbed time variation in the virtual height (left) and foF2 (right) at TIR during March, June and December 2015, respectively, from top to bottom. The red colour in the plots indicates the disturbed time variation, while blue colour indicates the quiet time variation. Here, Ap $>15$ is used as a threshold to distinguish the disturbed and quiet days. From the virtual height variations in the figure, it can be noticed that virtual height enhancement during quiet time is seen mostly in the evening hours, peaking at 20 IST, due to strong prevailing Pre-Reversal-Enhancement (PRE) conditions during March and December. However, weak PRE exists in the evening during June. There is also strong enhancement in the virtual height in the post-midnight during both quiet and disturbed days in June. From the height variations, it can be seen that post-midnight and pre-sunrise sector rise in the virtual height are more prominent during June and December 2015 than during March. During 
March, it is seen that the virtual height enhancement is seen only during the pre-midnight sector and afterwards no major deviations can be noticed in virtual height variations. The reduction of PRE during disturbed times can be seen very clearly during March. The temporal variation of foF2 $(\mathrm{MHz})$ during March, June and December suggests that the strong reduction of density as seen in March and December is due to higher PRE during March and December. No such reduction is seen during June. On the other hand, secondary enhancement in the density is prominently seen around the midnight sector during March. Such secondary enhancement is not seen during the June and December seasons. However, interestingly, it can be seen that while there exists a strong tendency toward a reduction in the density during June on disturbed days, there exists a strong tendency for an increase in density during December on disturbed days.

Now we present variation of GPS TEC as obtained from the Madrigal website based on the GPS TEC data from International GPS stations (IGS) during these three storms. The RINEX data has been obtained using Global IGS stations and the TEC data has been well calibrated (see Rideout and Coster, 2006 and Vierinen et al., 2015). Figure-10(a-c) shows the typical examples of latitude and longitude variation of global mean GPS TEC during these three major storms at selected time intervals. While Figure-10a shows the global TEC variations on 17 March 2015 at 12-12:20 UT, Figure-10b and 10c show the global TEC variations at 21 21:20 UT on 22 June and at 04:20-04:40 UT on 21 December, respectively. From the figure, it can be seen that a strong enhancement of TEC in the TEC map at 12 UT over the Indian sector coincides with the rising phase of the $\mathrm{AE}$ index. At the same time, we can notice that there is an increase of foF2 over Tirunelveli. This could be due to IMF Bz turning northward from southward as seen in Figure-1. Northward turning of IMF Bz can cause penetration of the westward electric field which can support an increase of density and TEC over the equator, but decrease density at crest regions. So, we believe that the combination of the usual eastward electric field with a westward penetration electric field could produce such a phenomenon.

Now we discuss the TEC variations in the other events. Figure-10b shows that there is a decrease of TEC over the entire Indian region. At the same time, we see an abrupt decrease of foF2 over Allahabad, Hyderabad and Tirunelveli stations suggesting negative storm effect in both foF2 and TEC observations. Figure-10c shows the TEC observations of positive storm effect on 21 December at 04:20-04:40 UT. The same type of results can be seen in the foF 2 variations where we see wavetype density fluctuations which seem to be associated with $\mathrm{AE}$ fluctuations.

We now examine the GUVI satellite data of daytime $\mathrm{O} / \mathrm{N}_{2}$ column density as obtained from the GUVI instrument to study the changes in thermosphere composition during these three storms. Figure-11(a-c) shows the global $\mathrm{O} / \mathrm{N}_{2}$ ratio as obtained using GUVI satellite observations during 18 March, 23 June and 21 December, respectively. The $\mathrm{O} / \mathrm{N}_{2}$ ratio is determined from the $\mathrm{O}(135.6 \mathrm{~nm})$ and $\mathrm{N}_{2}(\mathrm{LBH})$ using dayglow emissions with $1.75^{\circ}$ X $1.75^{\circ}$ spatial resolution (e.g., Christensen, 2003; Strickland et al., 2004). The GUVI column $\mathrm{O} / \mathrm{N}_{2}$ ratio provides information on the changes in the composition due to these storms. If the $\mathrm{O} / \mathrm{N}_{2}$ ratio is reduced (increased) in the map, it shows the increase of molecular $\mathrm{N}_{2}(\mathrm{O})$. If $\mathrm{N}_{2}$ increases at low latitudes, it can cause negative storms due to the reduction of atomic oxygen density. During 18 March, a decrease of $\mathrm{O} / \mathrm{N}_{2}$ ratio can be seen over China and Australia longitudes. This can cause negative ionospheric storm effects at these longitudes. As Indian longitude is close to China and Australian longitudes, we believe we are seeing the negative ionospheric storm during storm recovery in the data from the ALD, HYD and TIR stations. In general, there is a reduction of $\mathrm{O} / \mathrm{N}_{2}$ ratio at low latitudes during the entire day on $18 \mathrm{March}$ suggesting that there could be compositional changes affecting the low latitudes. The TEC observations as shown by Ramsingh et al.
(2015) suggest that at low latitudes negative storm effect prevails while positive storm effect prevails at equatorial stations. These observations also suggest that compositional changes could be modifying the density during this storm. Figure-11b and $11 \mathrm{c}$ show the $\mathrm{O} / \mathrm{N}_{2}$ ratio during the June and December storm events. It can be seen that the $\mathrm{O} / \mathrm{N}_{2}$ ratio has been reduced drastically in the northern hemisphere during the June storm. However, the opposite signature is seen during the December storm where it is seen that $\mathrm{O} / \mathrm{N}_{2}$ ratio has been reduced in the southern hemisphere compared to the northern hemisphere. These observations suggest that the $\mathrm{O} / \mathrm{N}_{2}$ ratio is also playing a role in the positive/negative storm effect at low latitudes as seen during these three major storms.
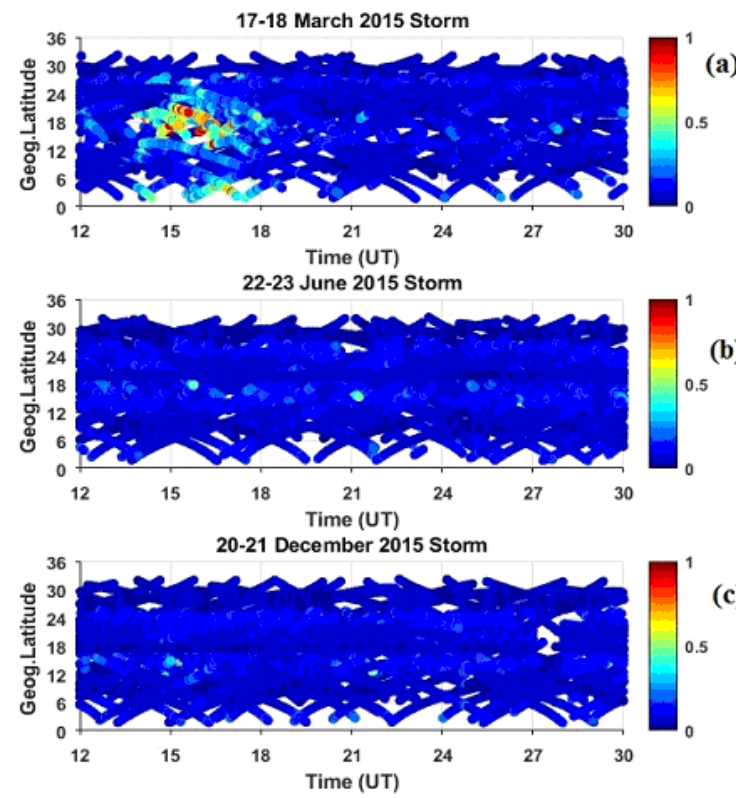

Figure-6(a-c) shows the spatial and temporal variation of L-band scintillations (S4 Index) during (a) 17-18 March 2015, (b) 2223 June 2015 and (c) 20-21 December 2015 storm event. The colour code in the right hand side of the figure shows S4 index.

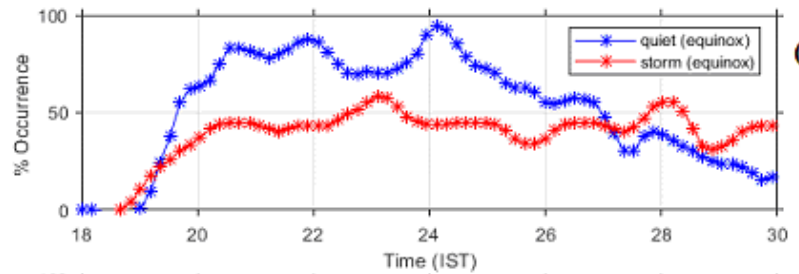

(a)

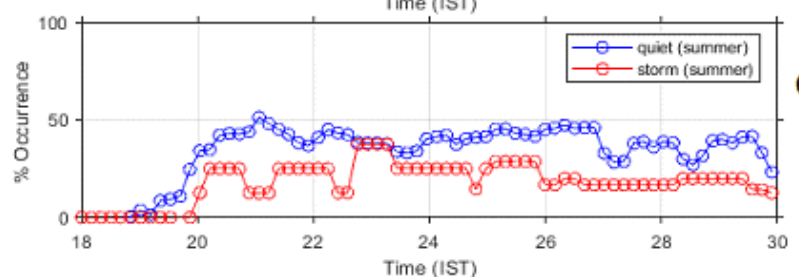

(b)

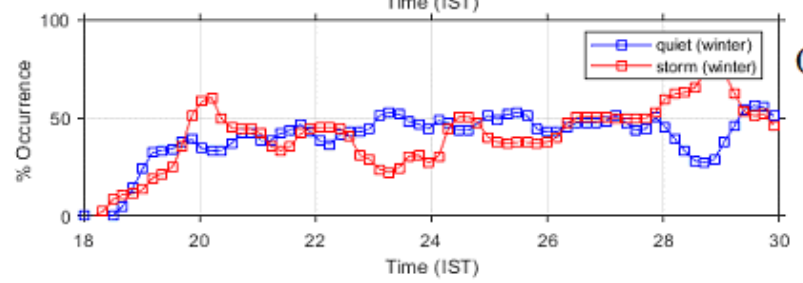

Figure-7(a-c) shows the temporal variation of quiet (blue) and disturbed (red) days equatorial spread $F$ (ESF) during (a) March 2015, (b) June 2015 and (c) December 2015 months

We show some important ionospheric effects as seen over the Indian sector during major space weather events in March, June and December 2015 respectively in Table-2. 
Table-2 shows the comparison of important ionospheric effects as seen during March, June and December 2015 major space weather events over the Indian region.

\begin{tabular}{|l|l|l|l|}
\hline Parameter & March storm & June storm & December storm \\
\hline h'F $(\mathrm{km})$ & $\begin{array}{l}\sim 560 \mathrm{~km} \text { increase in h'F }(\mathrm{km}) \\
\text { during PRE time due to } \\
\text { undershielding effect. The effect } \\
\text { is also seen at all the stations } \\
\text { simultaneously in India }\end{array}$ & $\begin{array}{l}\sim 200 \mathrm{~km} \text { decreased in h'F } \\
(\mathrm{km}) \text { is due to } \\
\text { undershielding effect but } \\
\sim 500 \mathrm{~km} \text { increased later due } \\
\text { to overshielding effect }\end{array}$ & $\begin{array}{l}\sim 600 \text { km increase in h'F } \\
\text { during dawn sector linked to } \\
\text { disturbance winds/electric } \\
\text { fields }\end{array}$ \\
\hline $\begin{array}{l}\text { Spread F/L-band } \\
\text { scintillations }\end{array}$ & $\begin{array}{l}\text { Yes at all the Indian stations. L- } \\
\text { band scintillations and TEC } \\
\text { fluctuations occurred. }\end{array}$ & $\begin{array}{l}\text { No spread F. Only localized } \\
\text { spread F at HYD station. No } \\
\text { L-band scintillations }\end{array}$ & $\begin{array}{l}\text { Spread F in the post-sunset } \\
\text { and dawn sectors. Weak L- } \\
\text { band scintillations and TEC } \\
\text { fluctuations }\end{array}$ \\
\hline $\begin{array}{l}\text { Positive/Negative } \\
\text { storm }\end{array}$ & $\begin{array}{l}\text { Positive storm observed at equator } \\
\text { but negative storm at low latitudes }\end{array}$ & $\begin{array}{l}\text { Negative storm observed at ath equator and low } \\
\text { both } \\
\text { latitudes }\end{array}$ & $\begin{array}{l}\text { Positive storm observed at } \\
\text { both equator and low } \\
\text { latitudes }\end{array}$ \\
\hline $\begin{array}{l}\text { Time of the maximum } \\
\text { impact }\end{array}$ & Evening/post-sunset & Post-midnight & Dawn sector \\
\hline
\end{tabular}

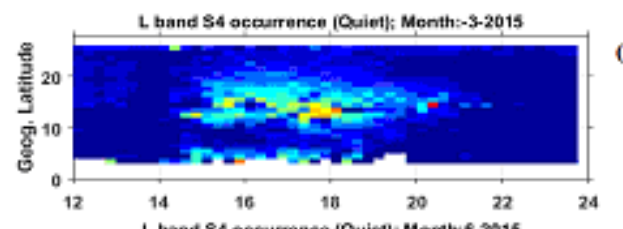

(n)
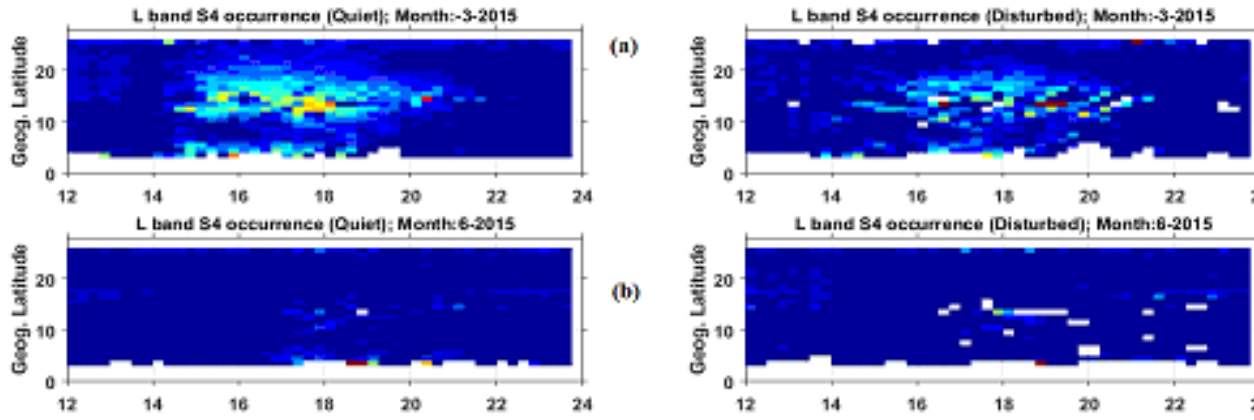

(b)
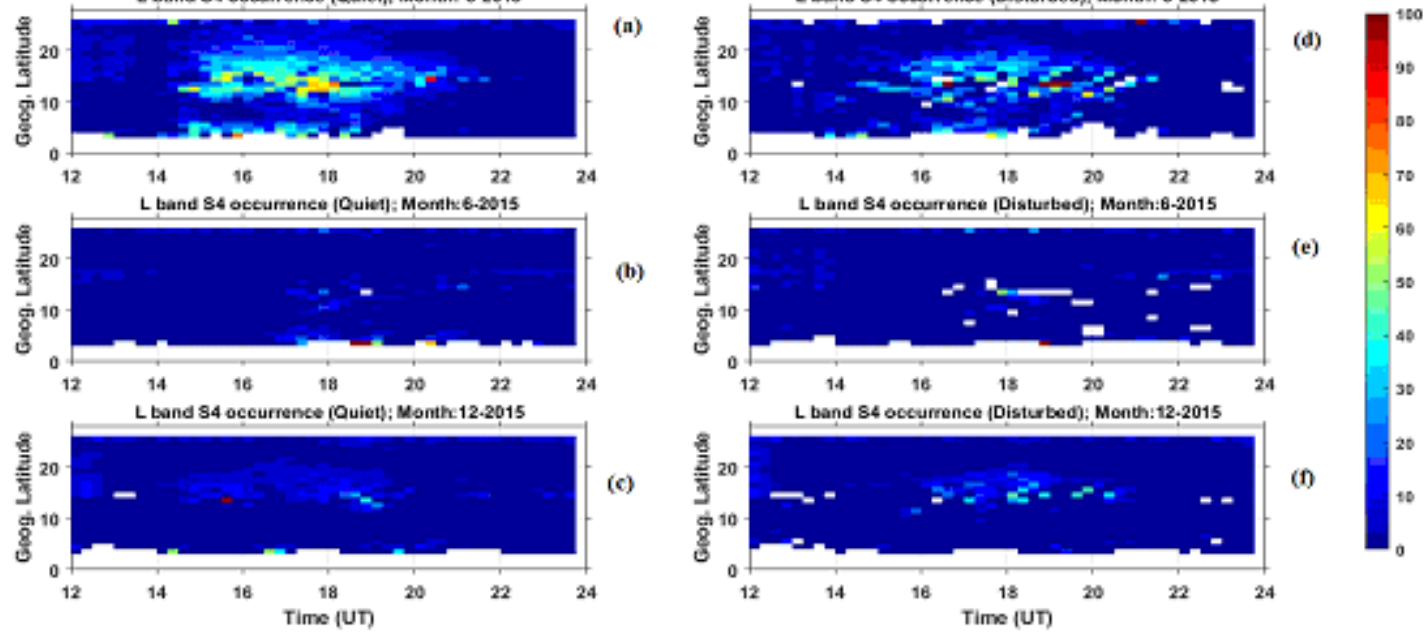

Figure-8(a-f) shows the spatial and temporal variation of quiet (left plots) and disturbed (right plots) days percentage occurrence of Lband scintillations during (a) March 2015, (b) June 2015 and (c) December 2015
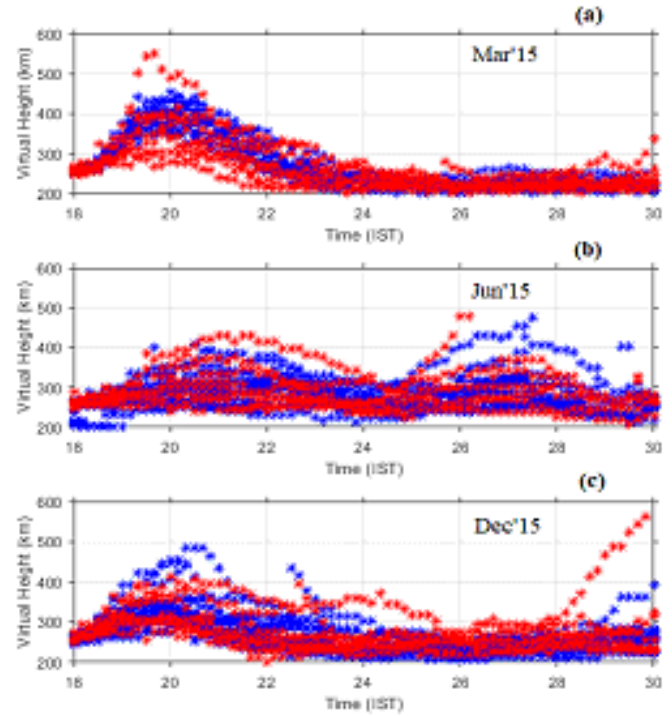

Figure-9(a-f) shows the temporal variation of quiet (blue) and disturbed (red) days h'F (km) (left) and foF2 (MHz) (right) at TIR during

(a) March, (b) June and (c) December 2015
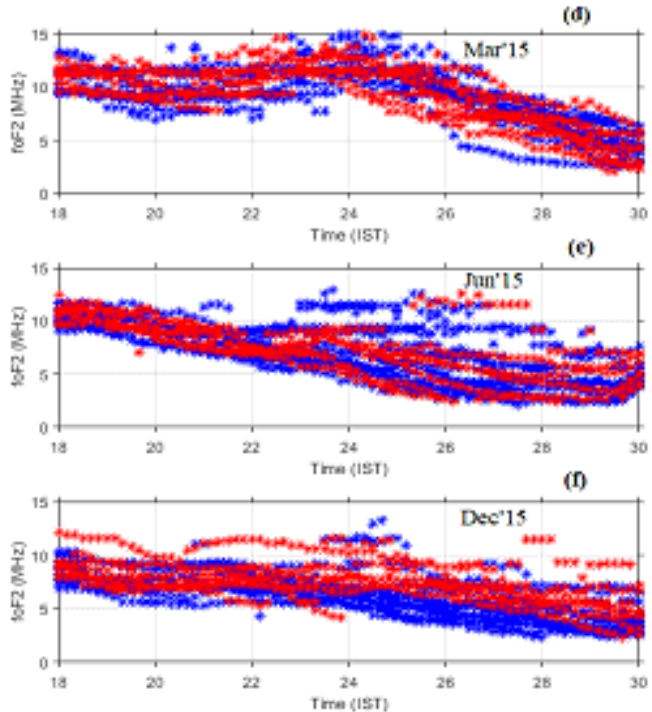

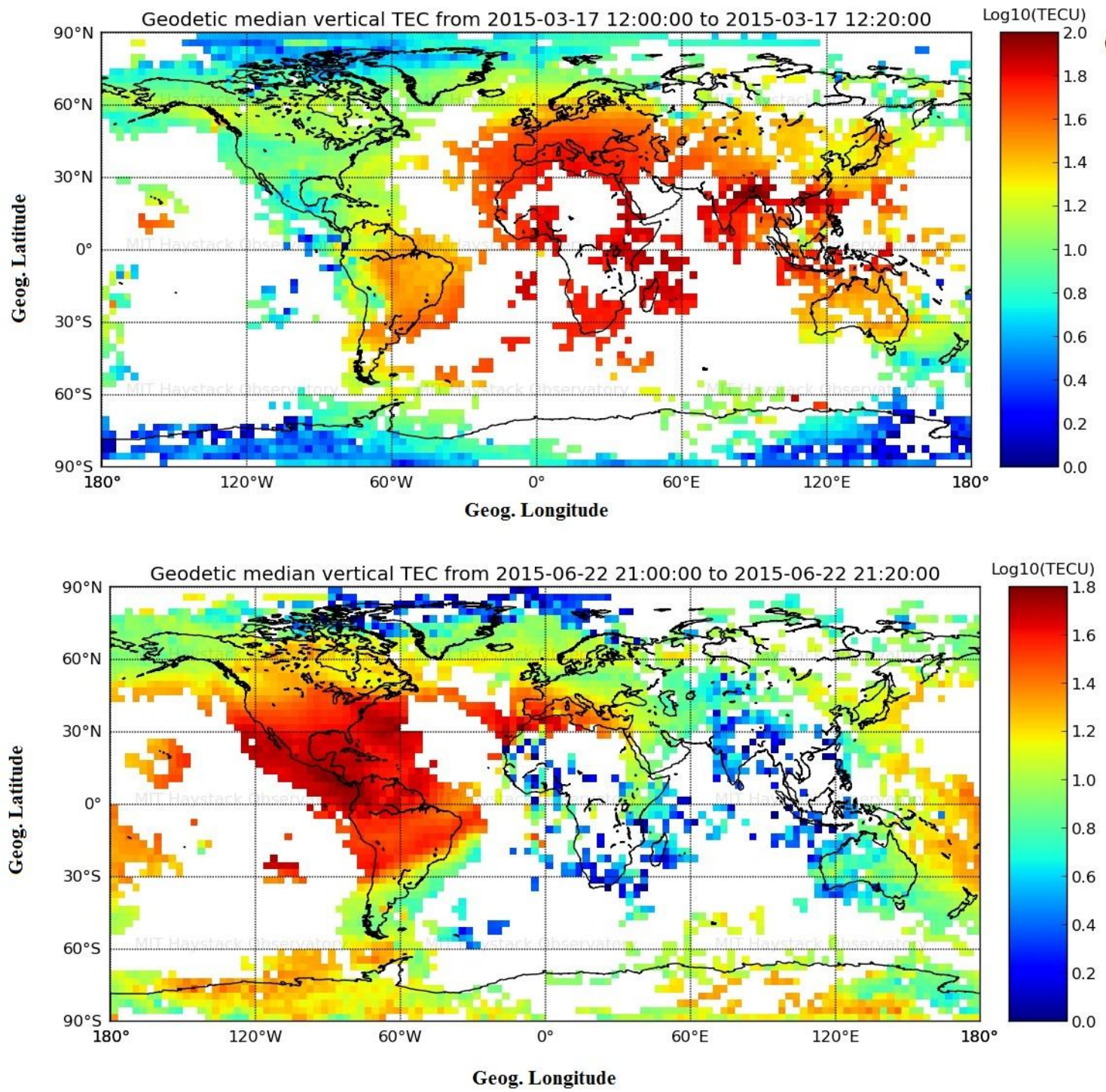

(a)

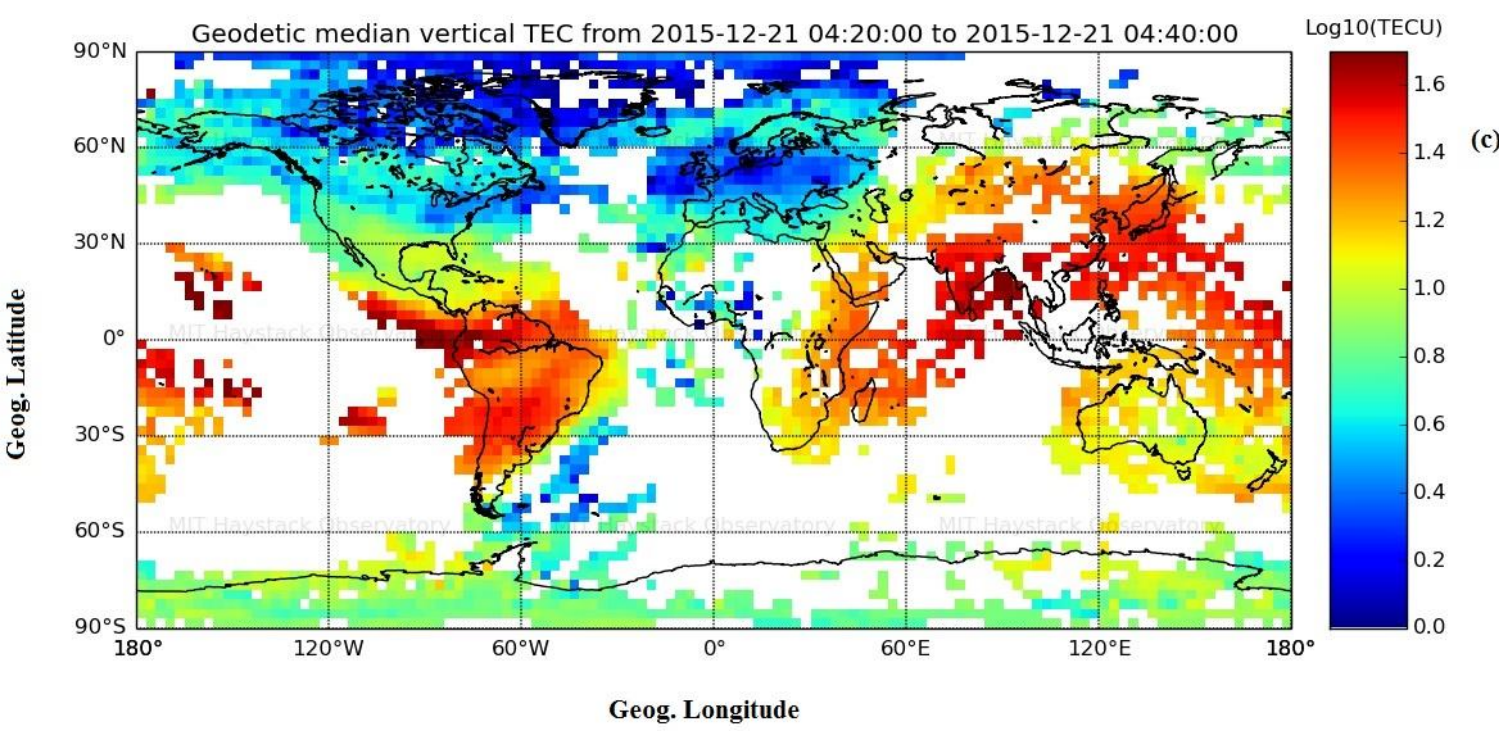

Figure-10(a-c) shows the latitude and longitude variation of mean TEC at selected times during (a) 17-18 March 2015, (b) 22-23 June 2015 and (c) 20-21 December 2015 

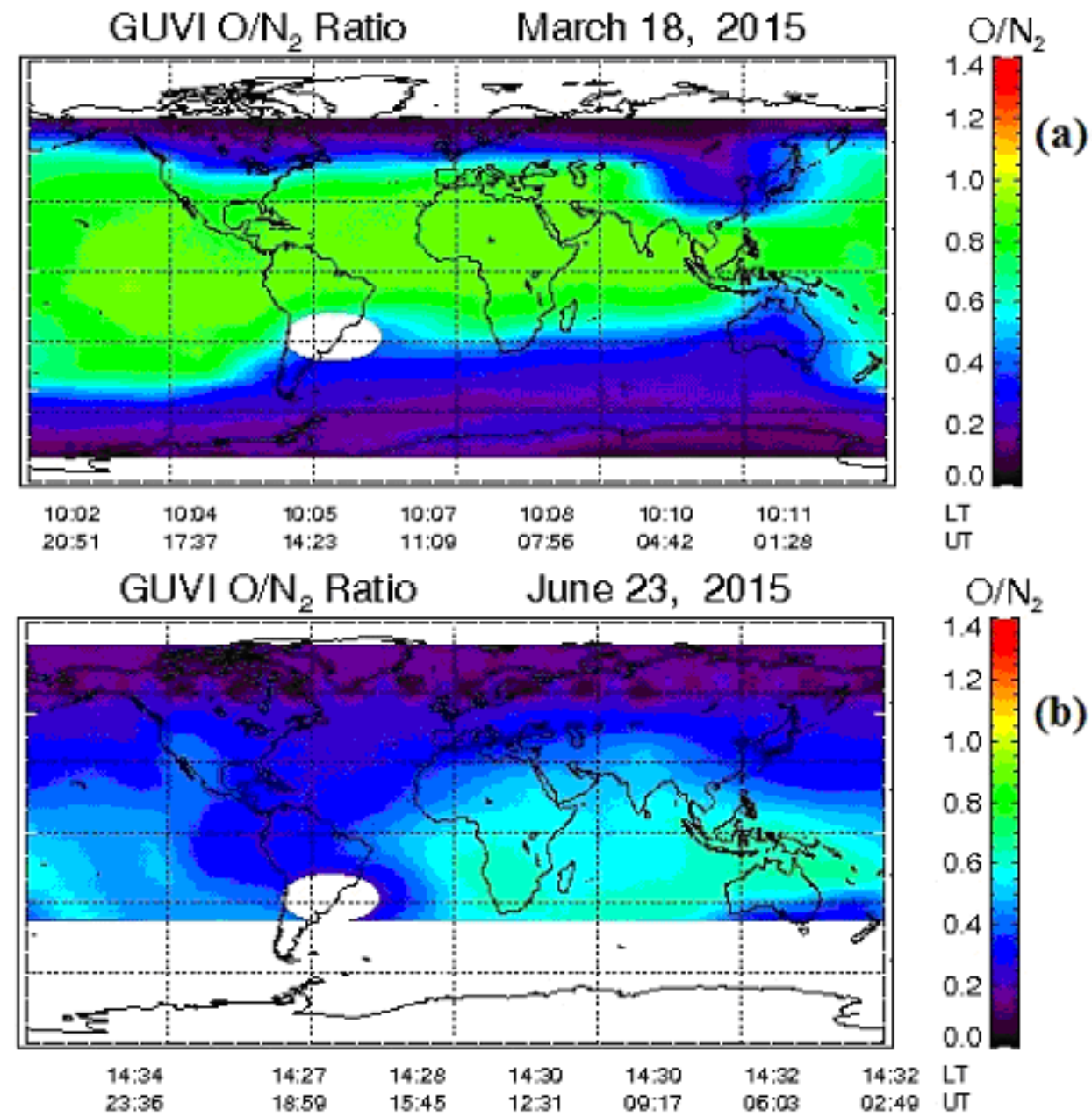

GUVI O/ $\mathrm{N}_{2}$ Ratio Dec 21, 2015
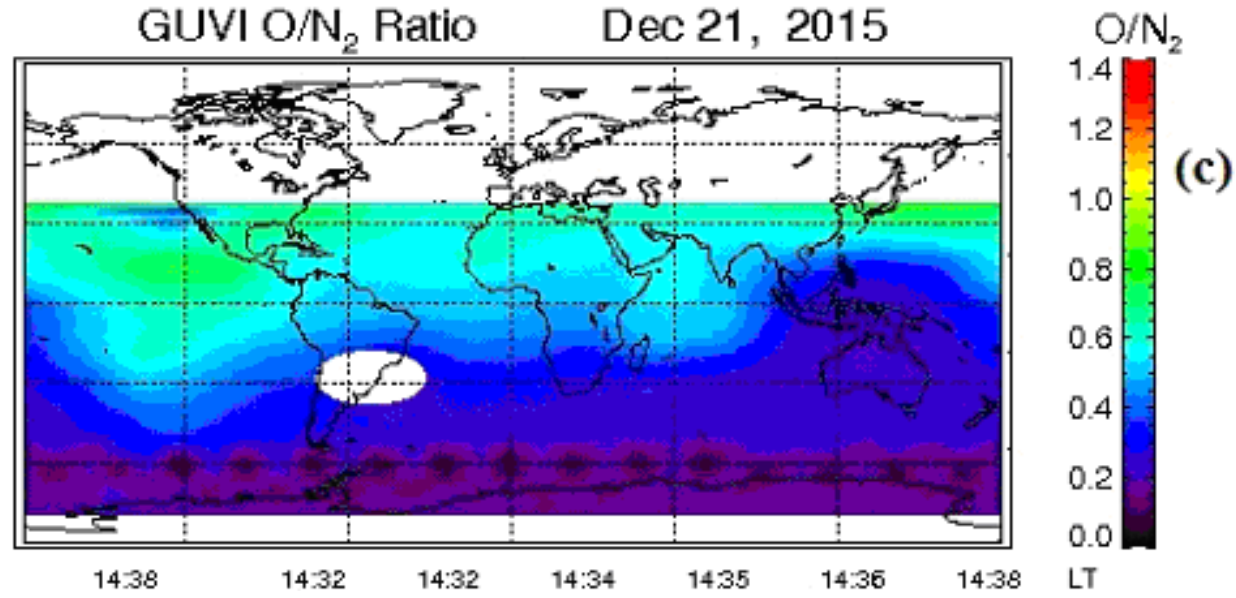

Figure-11(a-c) shows the latitude and longitude variation of mean O/N2 ratio during (a) 17-18 March 2015, (b) 22-23 June 2015 and (c) 20-21 December 2015

\section{Results and Discussion}

Now we will compare and discuss the analysis of the results that we have presented based on ionosondes and GPS receivers using three major storms which are typically representative of three major seasons over the Indian sector. The St. Patrick's Day geomagnetic storm on 17 March 2015 in the equinox season is a unique storm where we have a observed rise of the $\mathrm{F}$ layer height in the evening sector at all ionosonde stations. This rise in height often as PRE in the zonal electric field has caused additional drift to the existing upward drift of the $\mathrm{F}$ region during the equinox that pushed the $\mathrm{F}$ layer to as high as $560 \mathrm{~km}$. This led to the generation of severe spread $\mathrm{F}$ in the ionograms from the equator to the anomaly crest region only over the Indian longitude sector. It is believed that local PRE coincided with the PP electric field for this event, and caused an abrupt increase of upward vertical drift of $\sim 70 \mathrm{~m} / \mathrm{s}$. This also caused intense scintillations at several latitudes in the Indian longitudes. It is known that low latitude Es layers play a significant role in evening PRE increase. Accordingly, when we examined the Es layers at the low latitude station Hyderabad, we did not see strong Es layers during the time of the abrupt increase of PRE for the 17-18 March storm, which again suggests that the absence of a low latitude Es layer at the same could also have increased the upward vertical drift. On the other hand, during the June storm, we observed an abrupt decrease of the F layer height to as low as $200 \mathrm{~km}$ and then again it went up 
to $500 \mathrm{~km}$ in a span of half an hour at local midnight at all the three stations due to undersheilding and overshielding electric fields. It is known that undershielding electric fields cause penetration of the westward electric field in addition to the already existing westward electric field. This caused an abrupt decrease in the F layer height. However, this couldn't produce any spread F at the TIR station but led to generation of localized spread $F$ at the HYD station during this period. This may be due to sharp density gradients at this location or it could have drifted in from other locations. In addition, interestingly, we have observed density reduction near midnight as compared to quiet time density at all the stations indicating negative storm effect. This reduction is significant at Allahabad station indicating the role of composition. This reduction is also noticed in the GPS TEC map during the same time over Indian longitude. Fuller-Rowell et al. (1994) suggested that negative storms are caused mainly by increased molecular Nitrogen density during daytime, however, their strength depends on the longitude and local time sector. As we observe negative density during both daytime and nighttime for the June storm, we believe that increased molecular Nitrogen density continued to affect the low latitude densities. On the other hand, during the December 2015 storm, we observed large scale density and height fluctuations at low latitude stations. In addition, this storm produced oscillatory PRE over the TIR station in the evening sector that produced spread $\mathrm{F}$ for a few hours in the premidnight hours. However, in the dawn sector, it again caused a sudden rise in the virtual height at all the stations simultaneously. This rise in the height produced fresh generation of spread $\mathrm{F}$ at both the equatorial station as well as low latitude stations.

The comparative study suggests that more ESF irregularities were present in the post-sunset sector during the March storm than during the June and December storms. It is known that during March, the PRE is high due to prevailing background conditions and can cause generation of ESF. In addition, as the background density is higher during March equinox, it is possible that it could also cause enhanced density gradients at the bottomside that can positively impact the spread $F$ occurrence. However, investigations suggest that such increase in the PRE electric fields are not seen at nearby longitudes as quiet time ionospheric electric fields are possibly modified by disturbance dynamo electric fields in addition to undershielding electric fields (e.g., Patra et al., 2016). It is known that as DD electric fields are opposite to PP electric fields, they can balance the penetration electric fields and can reduce or nullify the effect of penetration on the drifts as well as latitudinal extent. On the other hand, Bhattacharyya et al. (2019) suggested that enhanced ion-neutral collision frequency due to enhanced thermospheric atomic oxygen concentration during the recovery phase of the 17 March 2015 storm can restrict the latitudinal extension of plasma bubbles. Unlike the June storm in the European sector where scintillations have been extended to mid-latitudes, no significant shift was seen in the latitudinal extension of ESF and scintillations during the 17 March 2015 storm which suggests that such enhanced ion-neutral collisions could reduce latitudinal extent. During the December storm, we have seen increased spread $F$ occurrence in the post-midnight sector. However, ESF irregularities seem to be unaffected during the June storm. The analysis of GPS L-band scintillations over the Indian sector also suggests that they are more dominant during the March storm than during the other two storm events. In general, there is a tendency for suppression of plasma irregularities in the post-sunset but generation of post-midnight plasma irregularities during geomagnetic storms. But we noticed that there is a seasonal trend in suppression (generation) of post-sunset (post-midnight) ESF irregularities during these three major storms. Accordingly, the occurrence characteristics of both ESF irregularities and Lband scintillations during March, June and December are investigated by separating them into quiet and disturbed days. From the analysis, it can be seen that during disturbed days, occurrence of spread $\mathrm{F}$ during pre-midnight is reduced most significantly during March, and then during June. However, during December, there is a slight increase in spread F occurrence during both pre-midnight and post-midnight to pre-sunrise hours. Interestingly, it can be noted that such an increase in spread $\mathrm{F}$ occurrence during pre-sunrise can be seen during March as well. However, spread F occurrence during June seems to be reduced significantly during both post-sunset as well as post-midnight sectors. Occurrence of L-band scintillations during these months suggests that they also follow the trend of the ionosonde observations.

During the main phase, the sudden increase of TEC and density on 17 March 2015 was caused by additional ionization due to westward penetration of IEFy electric fields to equatorial and low latitudes. The post-midnight enhancement of density at the equator with a reduction of density at Hyderabad and Allahabad could be due to readjustment of density by equatorward thermospheric meridional winds. We have also noticed a sudden anomalous increase of density and TEC in the early hours of 18 March 2015. During this period, we don't see any variations in the IMF $\mathrm{Bz}$ and $\mathrm{AE}$ index suggesting that they could not cause any density increase. However, since it is in the recovery phase, we believe that combination of disturbance winds and waves or compositional changes could have caused such increase. Such short term increase in density and TEC also has been noted during the other two storms as well. On 18 March, we have seen a reduction of Equatorial Ionization Anomaly (EIA) crests and density reduction during daytime due to a combination of changes in composition and wind-induced westward electric fields which caused positive storm effect at the equator but negative storm effect at low latitude. The virtual height variations during quiet and disturbed days in March suggest that height fluctuations were higher during disturbed days as compared to the quiet days; the height variations during disturbed days are distorted non-linearly in June and December. During March, the virtual heights were reduced on some of the nights due to the combined effect of PPEFs and DDEFs in the pre-midnight. On the other hand, the temporal variation of virtual height in December shows its increasing trend in the pre-sunrise hours during disturbed days. However, during June, it is seen that in addition to the post-sunset rise in the virtual height, increase of virtual height is seen in the post-midnight during both quiet and disturbed nights unlike other seasons.

To understand these results further, we have examined the background conditions under which these storms occurred. It is known that meridional winds blow poleward in the day and equatorward in the night during equinox season under geomagnetically quiet conditions. However, the meridional winds usually blow from summer hemisphere to winter hemisphere during solstice conditions depending upon the location of the subsolar point. In addition, during geomagnetic storms, additional energy in the high latitude causes composition and winds to blow to mid and low latitudes. This modifies the existing composition and winds at these mid and low latitudes to create positive and negative ionospheric storms at these latitudes. It is noticed that while negative ionospheric storm effect is seen in the summer hemisphere, positive ionospheric storm effect is seen during winter at low latitudes. It is believed that the increase of molecular Nitrogen $\left(\mathrm{N}_{2}\right)$ density or decrease of the $\mathrm{O} / \mathrm{N} 2$ ratio at mid and low latitudes causes a reduction of ion density due to faster recombination over the summer hemisphere. On the other hand, in the winter hemisphere, it causes a reduction of equatorward winds due to trans-equatorial winds blowing from the summer hemisphere to the winter hemisphere, which causes an increase of ion density in the winter hemisphere and produces positive ionospheric storms. However, the zonal electric fields as modified by the additional contributions from the storm time electric fields can also play significant role in modifying the density at equator and low latitudes, and can cause positive and negative storms at these low latitudes (Balan et al., 2010). Singh and Sripathi (2017) 
have studied the undershielding and overshielding effect on the June storm over the Indian sector using ionosondes and GPS receivers. They noticed the absence/presence of Es layers as per the orientation of IEFy electric fields and reduction of foF2 and TEC due to negative storm effects. Kil et al. (2003) have investigated the 15 July 2000 major storm using ground and space based observations where they have seen seasonal effects in their observations. They showed negative storm effect in the summer hemisphere with positive storm effect in the winter hemisphere. They showed expansion of northern negative storm phase rapidly to the equator in the midnight and even to opposite hemisphere. They further suggested that uplift of the ionosphere due to storminduced equatorward wind is the primary reason for the positive storm, rather than compositional change. Balan et al. (2010) further suggested that strong positive storms are observed mostly in the longitudes where onset of the geomagnetic storm falls in the ionization-production-dominated morning-noon sector which happened to be in the Japanese-Australian longitude during the 07-08 November 2004 super geomagnetic storm. Also, the combination of meridional winds and steep upward drifts from eastward prompt penetration electric fields during daytime at equatorial and low latitudes can cause production of additional ionization leading to the positive storms at these latitudes. They also can cause generation of $\mathrm{F}^{3}$ layers at these low latitudes during the morning-noon main phase. Vijayalekshmi et al. (2011) have studied the seasonal variation of positive and negative ionospheric storms using foF2 measurements by two ionosondes located in Boulder, USA and Kokubunji, Japan during 1985-2005 that cover solar cycles 22/23. Their results suggest that negative storms follow the solar cycle better than positive storms, while positive storms preferably occur around morning-noon. Their results also suggest preferential occurrence of storm main phase around UT midnight for major storms. They suggested that solar windmagnetosphere coupling could be more effective in this UT zone (Pacific sector) where the separation between geomagnetic and geographic equators is minimum but declination angle is steady. However, when we examined our observations, we realize that main phase of our storms occurred at different UT times with different lengths. Therefore, we do not have any statistical details on such preferential onset of the main phase of the storms. We would like to investigate our data to check time preference for storms in the future. However, we can certainly see that positive and negative storms in our observations do follow seasonal trend as shown by Vijayalekshmi et al. (2011). In addition, we notice that positive storms are observed mainly during the onset of the December storm that falls under the morning-noon sector. This is due to the fact that though the $\mathrm{AE}$ index is lower during the November storm than the other two storms, this storm is prolonged for several hours longer than the other two storms which may possibly alter the composition in association with trans-equatorial meridional winds to produce positive storms.

The results presented here hence suggest that the equatorial and low latitude ionosphere is significantly affected by coupling of several high latitude processes by modifying the electric fields, winds and waves which affected the ESF irregularities significantly. We also noticed seasonal variation in composition changes in association with disturbance winds and disturbance electric fields which are responsible for several observed changes in the density and TEC in the low latitudes. The observations also suggest that while some of the observations of positive storm at the equator and negative storm at low latitude could be explained by disturbance dynamo electric fields, some of the observations of positive storms can be explained by undershielding electric fields to the equator. In the future, we will study these various effects through modelling aspects and compare them to observations. We are hopeful that we will initiate some modelling studies using SAMI2 or TIEGCM models to investigate the role of different winds and electric fields on the low latitude ionosphere.

\section{Summary and conclusions}

We have investigated the response of the equatorial and low latitude ionosphere to major space weather events during 17-18 March 2015 (i.e., the St. Patrick's Day storm), 22-23 June 2015 and 19-20 December 2015 using simultaneous observations of ionosondes and GPS scintillations over Indian region. As these storms occurred during equinox, summer and winter seasons, respectively, with near similar Dst index, we examined the effects of different background densities, winds and compositions on the ionospheric parameters. The composition, winds, waves and electric fields which are modified during these storms are found to affect the low latitude ionospheric density depending upon the season, time, phase strength and direction of the storm. We noticed positive (negative) storm in December (June) in the main phase. We also noticed positive (negative) storm at the equator (low latitude) during March in the recovery phase. They also caused suppression or enhancement of the plasma irregularities as per the orientation of electric fields. The St. Patrick's Day storm showed a remarkable increase of height $[\mathrm{hF}(\mathrm{km})]$ due to the addition of undershielding eastward electric field to the PRE electric fields in the post-sunset hours over Tirunelveli to cause plasma irregularities at wider latitudes right from the equator to anomaly crest region which is in contrast to other nearby longitudes where it is seen suppression. In contrast, during the June storm, the $\mathrm{F}$ layer suddenly decreased and plasma irregularities were suppressed in the Indian sector in the midnight sector. However, during the December storm, we observed a simultaneous increase in the virtual height at all the stations to cause the generation of ESF irregularities in the pre-dawn sector. Observations of GPS L-band scintillations over the Indian sector also suggest that scintillations were more intense during the St. Patrick's Day storm than other two storms. It is known that there exists a suppression of post-sunset plasma irregularities and generation of post-midnight plasma irregularities during geomagnetic storms. But we noticed some differences in the above classification. We noticed an existence of a seasonal trend in the occurrence of post-sunset and post-midnight plasma irregularities during geomagnetic storms. The seasonal results presented here suggest that occurrence of plasma irregularities during pre-midnight is mostly reduced in the March followed by June due to storm processes. However, there is a slight increase in the occurrence of plasma irregularities for both pre-midnight and post-midnight sectors during December due to storms, while occurrence of plasma irregularities during June storm seems to be reduced significantly during both sectors. Occurrence of L-band scintillations during these months also suggests that they also follow a similar trend as that of ionosonde observations. These results suggest that low latitude ionosphere is significantly modulated by the storm processes, more so during winter than other seasons possibly due to prolonged and efficient coupling of solar wind-magnetosphere-ionosphere

\section{Acknowledgements}

This work is supported by the in-house project at Indian Institute of Geomagnetism (IIG), Navi Mumbai, India. We would like to thank all the ACE SWEPAM, USA for providing the IMF $\mathrm{Bz}$ data, world data centre for geomagnetism (WDC), Kyoto University, Japan for providing SYM-H, Kp, Ap and AE indices. We would like to thank Mr. Buduru Suneel Kumar, in-charge, TIFR Balloon Facility, Hyderabad for providing Hyderabad CADI ionosonde data. The technical help from technical staff members at EGRL/KSKGRL/MO Nagpur are very much acknowledged. We thank Dr S Banola, TO-IV, IIG for scaling of ionograms for some events which are used in the present work. TIMED GUVI $\mathrm{O} / \mathrm{N} 2$ ratio maps are downloaded from TIMED GUVI at http://guvitimed.jhuapl.edu/.GPS TEC data products and access through the Madrigal distributed data system are provided to the community (http://www.openmadrigal.org) by the Massachusetts 
Institute of Technology (MIT) under support from US National Science Foundation grant AGS-1242204. Data for TEC processing is provided from the following organizations: UNAVCO, Scripps Orbit and Permanent Array Center, Institut Geographique National, France, International GNSS Service, The Crustal Dynamics Data Information System (CDDIS), National Geodetic Survey, Instituto Brasileiro de Geografia e Estatística, RAMSAC CORS of Instituto Geográfico Nacional de la República Argentina, Arecibo Observatory, Low-Latitude Ionospheric Sensor Network (LISN), Topcon Positioning Systems, Inc., Canadian High Arctic Ionospheric Network, Centro di Ricerche Sismologiche, Système d'Observation du Niveau des Eaux Littorales (SONEL), RENAG : REseau NAtional GPS permanent, GeoNet - the official source of geological hazard information for New Zealand, GNSS Reference Networks, Finnish Meteorological Institute, and SWEPOS - Sweden. Access to these data is provided by madrigal network via: http://cedar.openmadrigal.org/. We also would like to thank the reviewer, Dr. Susanna C. Finn, University of Massachusetts Lowell, USA for her positive and constructive suggestions which improved the quality of the manuscript significantly.

\section{References}

Abdu, M. A.: 1997, J. Atmos. Sol. Terr. Phys., 59, 1505-1519.

Bagiya, M. S., K. N. lyer et. al.: 2011, J. Geophys. Res., 116, A01303, doi:10.1029/2010JA015845.

Balan, N., K. Shiokawa, Y. Otsuka, T. Kikuchi, D. Vijaya Lekshmi, S. Kawamura, M. Yamamoto, and G. J. Bailey: 2010, J. Geophys. Res., 115, A02304, doi:10.1029/2009JA014515.

Bhattacharyya, A., Fedrizzi, M., Fuller-Rowell, T. J., Gurram, P., Kakad, B., Sripathi, S., \& Sunda, S.: 2019, J. Geophys. Res., 124. https: // doi.org/10.1029/2018JA025995.

Blanc, and Richmond, A. D. : 1980, J. Geophys. Res., 85, 1669.

Buonsanto, M. J.: 1999, Space Science Reviews, 88(3-4), 563-601.

Burns, A. G., Killeen, T. L., Carignan, G. R., and Roble, R. G. : 1995, J. Geophys. Res., 100( A8), 14661- 14671, doi:10.1029/94JA03235.

Christensen, A. B., et al.: 2003, J. Geophys. Res., 108, 1451, doi:10.1029/2003JA009918, A12.

Fuller-Rowell, T. J., Codrescu, M. V., Moffett, R. J., Quegan, S.: 1994, J. Geophys. Res., 99( A3), 3893- 3914, doi:10.1029/93JA02015.

Fuller-Rowell, T. J., Codrescu, M. V., Roble, R. G., \& Richmond, A. D.: 1997, in Magnetic Storms, Geophys. Monogr. Ser., vol. 98, edited by B. T. Tsurutani et al., pp. 203 - 225, AGU, Washington, D. C.

Hajkowicz, L. A.: 1990, Planetary and Space Science, 38.7: 913 923, https://doi.org/10.1016/0032-0633(90)90058-X.

Hapgood, M.: 2017, Space Weather, 15, doi: 10.1002/2017SW001638.

Kamide, Y., McPherron, R. L., Gonzalez, W. D., Hamilton, D. C., Hudson, H. S., Joselyn, J. A., Kahler, S. W., Lyons, L. R., Lundstedt, H., \& Szuszczewicz, E.: 1997, In B. T Tsurutani et al. (Eds.), Magnetic storms (pp. 1 19). Washington, DC: American Geophysical Union.

Kamide, Y., and Chian, A. C.-L.: 2007, Handbook of the SolarTerrestrial Environment, Springer, 10.

Kil, H., L. J. Paxton, X. Pi, M. R. Hairston, and Y. Zhang: 2003, J. Geophys. Res., 108(A11), 1391, doi:10.1029/2002JA009782.

Lastovicka, J., J. Atmos. Terr. Phys., Vol. 58, No. 7. pp. 831-843, 1996.

Lu, G., A.D. Richmond et al.: 1995, J. Geophys.Res., 100, 19,643.

Lu, G., Richmond, A. D., Roble, R. G., \& Emery, B. A.: 2001, J. Geophys. Res., 106(A11), 24493-24504.

MacDougall, J. W., Grant, I. F., and Shen, X.: 1995, Report UAG14: lonospheric Networks and Stations, World Data Center A for Solar-Terrestrial Physics, 21.

Mannucci, A. J., B. T. Tsurutani et al.: 2005, Geophys. Res. Lett., 32, L12S02, doi:10.1029/2004GL021467.

Mayr, H. G., Harris, I., \& Dube, M.: 1990, J. Atmos. Terr. Phys., 52(2), 103-112.

Mendillo, M. : 2006, Rev. Geophys., 44, RG4001, doi:10.1029/2005RG000193.
Prölss, G. W.: 1997, Magnetic storms, Geophysical Monograph 98 (pp. 183- 202). Washington, DC: American Geophysical Union.

Prölss, G. W.: 2017, Handbook of Atmospheric Electrodynamics (1995) (pp. 195-248).

Ram Singh\& Sripathi, S.: 2017, J. Geophys. Res., 122. https://doi.org/10.1002/2017JA024460.

Ram Singh, S. Sripathi, et al.: 2015, J. Geophys. Res., 120, $10,864-10,882$.

Richmond, A.D., and Matsushita, S.: 1975, J. Geophys. Res., 80, 2839-2850.

Richmond, A.D., G. Lu: 2000, J. Atmos. Sol. Terr. Phys., 62, 11151127.

Rideout, W. and A. Coster: 2006, GPS Solutions, DOI 10.1007/s10291-006-0029-5.

Rishbeth, H.: 1975, J. Atmos. Terr. Phys., 37, 1055-1064, doi: 10.1016/0021-9169(75)90013-6.

Sharma, A. S., Baker, D. N., Grande, M., Kamide, Y., Lakhina, G. S., McPherron, R. M., Reeves, G. D., Rostoker, G. , Vondrak, R., Zelenyiio, L.: 2003, The Storm-Substorm Relationship (eds A. S. Sharma, Y. Kamide and G. S. Lakhina). doi:10.1029/142GM01.

Somayajulu, V. V., BV Krishna Murthy, and K. S. V. Subbarao: 1991, J. Atmos. Terr. Phys., 53.10, 965-976.

Strickland, D. J., R. R. Meier, R. L. Walterscheid, J. D. Craven, A. B. Christensen, L. J. Paxton, D. Morrison, and G. Crowley: 2004, J. Geophys. Res., 109, A01302, doi:10.1029/2003JA010220.

Patra, A. K., P. P. Chaitanya, N. Dashora, M. Sivakandan, and A. Taori: 2016, J. Geophys. Res., 121, 11,518-11,527, doi:10.1002/ 2016JA023384.

Verkhoglyadova, O. P., et al.: 2016, J. Geophys. Res., 121, 89008923, doi: $10.1002 / 2016 \mathrm{JA022883}$.

Vichare, G., S. Alex, and G. S. Lakhina: 2005, J. Geophys. Res., 110, A03204, doi:10.1029/2004JA010418.

Vierinen, J. A. J. Coster, W. C. Rideout, P. J. Erickson, and J. Norberg: 2015, Atmos. Meas. Tech. Discuss, doi:10.5194/amtd-8-9373-2015.

Vijaya Lekshmi, D., N. Balan, S. Tulasi Ram, and J. Y. Liu: 2011, J. Geophys. Res., 116, A11328, doi:10.1029/2011JA017042.

Weiss, L. A., Reiff, P. H., Moses, J. J., Heelis, R. A., \& Moore, B. D.: 1992, NASA Technical reports.

Wolf, R. A.: 1975, Space Sci. Rev., 17, 537-562, doi: 10.1007/BF00718584.

Zhao, B., W. Wan, J. Lei, Y. Wei, Y. Sahai, and B. Reinisch: 2012, Ann. Geophys., 30, 831-840. 